\title{
Load Reduction, Demand Response and Energy Efficient Technologies and Strategies
}

\author{
PA Boyd \\ GB Parker \\ DD Hatley
}

November 2008

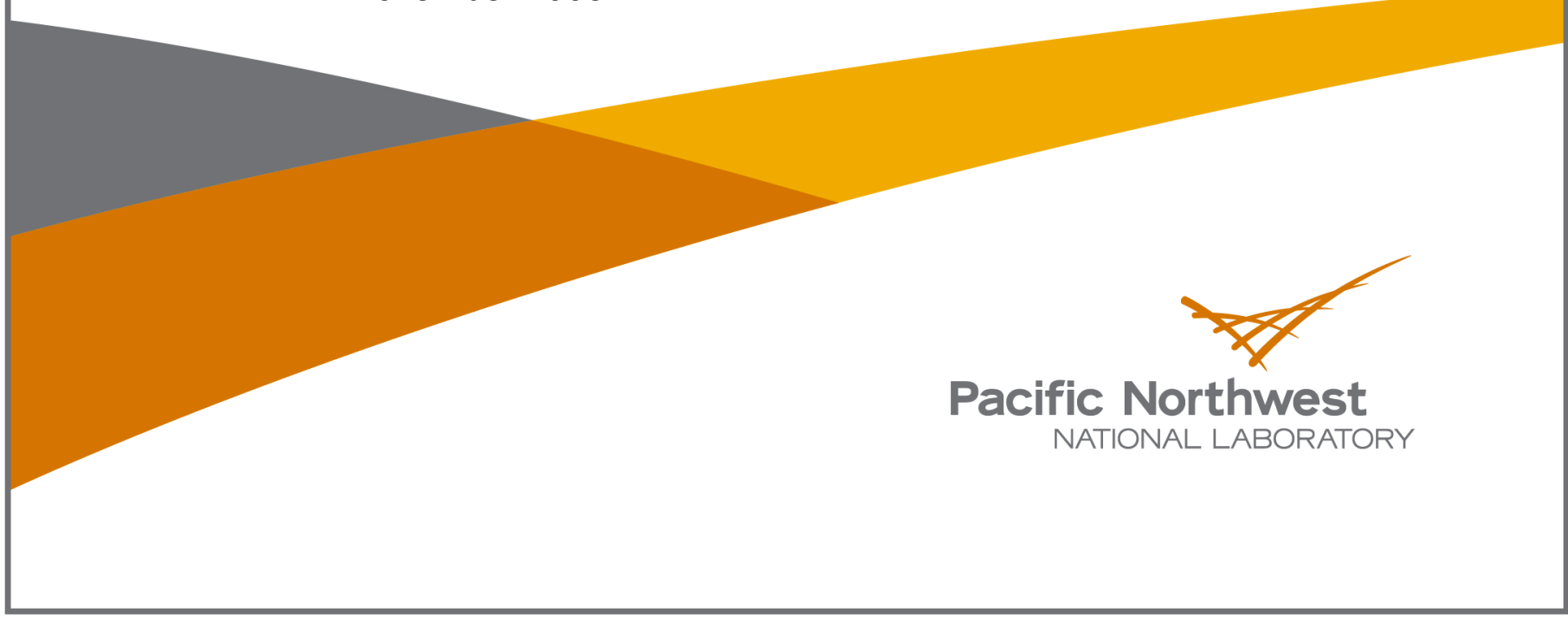




\title{
DISCLAIMER
}

This report was prepared as an account of work sponsored by an agency of the United States Government. Neither the United States Government nor any agency thereof, nor Battelle Memorial Institute, nor any of their employees, makes any warranty, express or implied, or assumes any legal liability or responsibility for the accuracy, completeness, or usefulness of any information, apparatus, product, or process disclosed, or represents that its use would not infringe privately owned rights. Reference herein to any specific commercial product, process, or service by trade name, trademark, manufacturer, or otherwise does not necessarily constitute or imply its endorsement, recommendation, or favoring by the United States Government or any agency thereof, or Battelle Memorial Institute. The views and opinions of authors expressed herein do not necessarily state or reflect those of the United States Government or any agency thereof.

\author{
PACIFIC NORTHWEST NATIONAL LABORATORY \\ operated by \\ BATTELLE \\ for the \\ UNITED STATES DEPARTMENT OF ENERGY \\ under Contract DE-AC05-76RL01830
}

Printed in the United States of America
Available to DOE and DOE contractors from the
Office of Scientific and Technical Information,
P.O. Box 62, Oak Ridge, TN 37831-0062;
ph: (865) 576-8401
fax: (865) 576-5728
email: reports@adonis.osti.gov

\begin{abstract}
Available to the public from the National Technical Information Service,
U.S. Department of Commerce, 5285 Port Royal Rd., Springfield, VA 22161

ph: (800) 553-6847

fax: (703) 605-6900

email: orders@ntis.fedworld.gov

online ordering: http://www.ntis.gov/ordering.htm
\end{abstract}

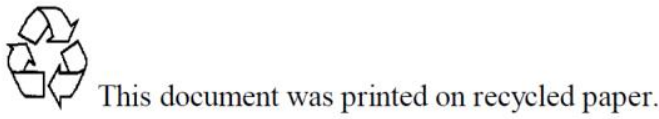




\title{
Load Reduction, Demand Response and Energy Efficient Technologies and Strategies
}

\author{
PA Boyd \\ GB Parker \\ DD Hatley
}

November 2008

Prepared for

the U.S. Department of Energy

under Contract DE-AC05-76RL01830

Pacific Northwest National Laboratory

Richland, Washington 99352 



\section{Executive Summary}

The Department of Energy's (DOE's) Pacific Northwest National Laboratory (PNNL) was tasked by the DOE Office of Electricity (OE) to recommend load reduction and grid integration strategies, and identify additional demand response (energy efficiency/conservation opportunities) and strategies at the Forest City Housing (FCH) redevelopment at Pearl Harbor and the Marine Corps Base Hawaii (MCBH) at Kaneohe Bay. The goal was to provide FCH staff a path forward to manage their electricity load and thus reduce costs at these $\mathrm{FCH}$ family housing developments.

The initial focus of the work was at the MCBH given the MCBH has a demand-ratchet tariff, relatively high demand ( $\sim 18 \mathrm{MW})$ and a commensurate high blended electricity rate $(26 \mathrm{cents} / \mathrm{kWh})$. The peak demand for MCBH occurs in July-August. And, on average, family housing at MCBH contributes $\sim 36 \%$ to the $\mathrm{MCBH}$ total energy consumption. Thus, a significant load reduction in family housing can have a considerable impact on the overall site load.

Based on a site visit to the $\mathrm{MCBH}$ and meetings with $\mathrm{MCBH}$ installation, $\mathrm{FCH}$, and Hawaiian Electric Company (HECO) staff, the following are recommended actions - including a "smart grid" recommendation - that can be undertaken by $\mathrm{FCH}$ to manage and reduce peak-demand in family housing. The reduction in peak load in $\mathrm{FCH}$ family housing will in turn also allow an overall reduction in $\mathrm{MCBH}$ peak demand depending on how the $\mathrm{MCBH}$ implements demand management strategies in $\mathrm{MBCH}$ commercial buildings. Recommendations are also made to reduce overall energy consumption - and thus reduce demand in FCH family housing.

\section{FCH Smart Grid Recommendations}

- Design and install a smart grid architecture for FCH that will produce price signals such as day- or hour- ahead demand prices from central controllers. These signals would be relayed via power-line or wireless communications to "smart" in-unit controllers or end-consumer devices such as thermostats, air conditioner compressor controllers, dryers, dishwashers and refrigerators - the home's major energy-users. The devices will process the information and respond by either shutting down at the appropriate time (e.g., turning off an air conditioner compressor) and/or not be allowed to turn on at the peak load time (e.g., thermostat-control of air conditioner). Additional features of, or options for, such a system include:

- Visualization technology in the living unit to provide the occupant the necessary and sufficient information on energy use and cost, and also provide occupant control over energy consumption in real time if that is part of a comprehensive smart grid strategy. A smart grid strategy in FCH would need to be tied into the MCBH load management system given the peak load (and peak demand cost) is a combination of the peak of the FCH and MCBH buildings.

- Extending the existing Two-Way Automatic Communication System (TWACS ${ }^{\circledR}$ ) infrastructure capability already in place at the MCBH to enable the implementation of smart grid remote load control in the FCH. If the TWACS is extended into $\mathrm{FCH}$, the system would require a smart meter capable of accepting the TWACS Disconnect Switch Interbase (DSI). The smart meter should also be capable of communicating (one-way) energy consumption (billing) data to FCH's provider of monthly consumption data. 
- The TWACS or similar system could be interfaced with an in-unit network and display to allow the occupants in each unit to make intelligent choices on how they use energy (and water) and/or provide energy- and water-using device control. The in-home network can use power-line carrier or radio-frequency technology or use low-voltage hard-wire to provide one-way and two-way communication with family housing residents.

- Work with HECO to utilize the capability of the HECO EnergyScout air conditioner controller that will be installed on each new/redeveloped living unit at FCH. HECO deploys the EnergyScout to turn off air conditioners during system-wide peak periods and has agreed to work with FCH and $\mathrm{MBCH}$ to consider interfacing the Energy Scout with a future FCH smart grid system to turn off air conditioners in response to the $F C H / M C B H$ load center (site) peak demand.

- Should HECO develop and offer an incentive program for solar/PV for family housing (as they at one time were considering in early 2000), then FCH should take advantage of any program and install PV systems for family housing. FCH should continually undertake cost/benefit analysis and plan for PV installations - and the integration of PV into the family housing smart grid architecture.

- Because the future mix of HECO generation resources includes more intermittent (non-base load) wind and central as well as distributed solar, $\mathrm{FCH}$ and $\mathrm{MCBH}$ should consider on-site energy storage strategies and (as part of the smart grid) control to maximize the value of storage to both reduce peak load as well as for site energy security. Near-term energy storage strategies to consider include a fleet of plug-in hybrid vehicles and large battery arrays.

A smart grid architecture that includes the features noted above is shown in Figure ES.1. This architecture includes the potential future integration of renewable energy generation sources at the utility (grid) level as well as at the load center (MCBH or $\mathrm{FCH}$ ) and/or at the individual living units (e.g., rooftop PV). It also includes the integration of energy storage (for renewable generation) and PHEV technology as future considerations. 


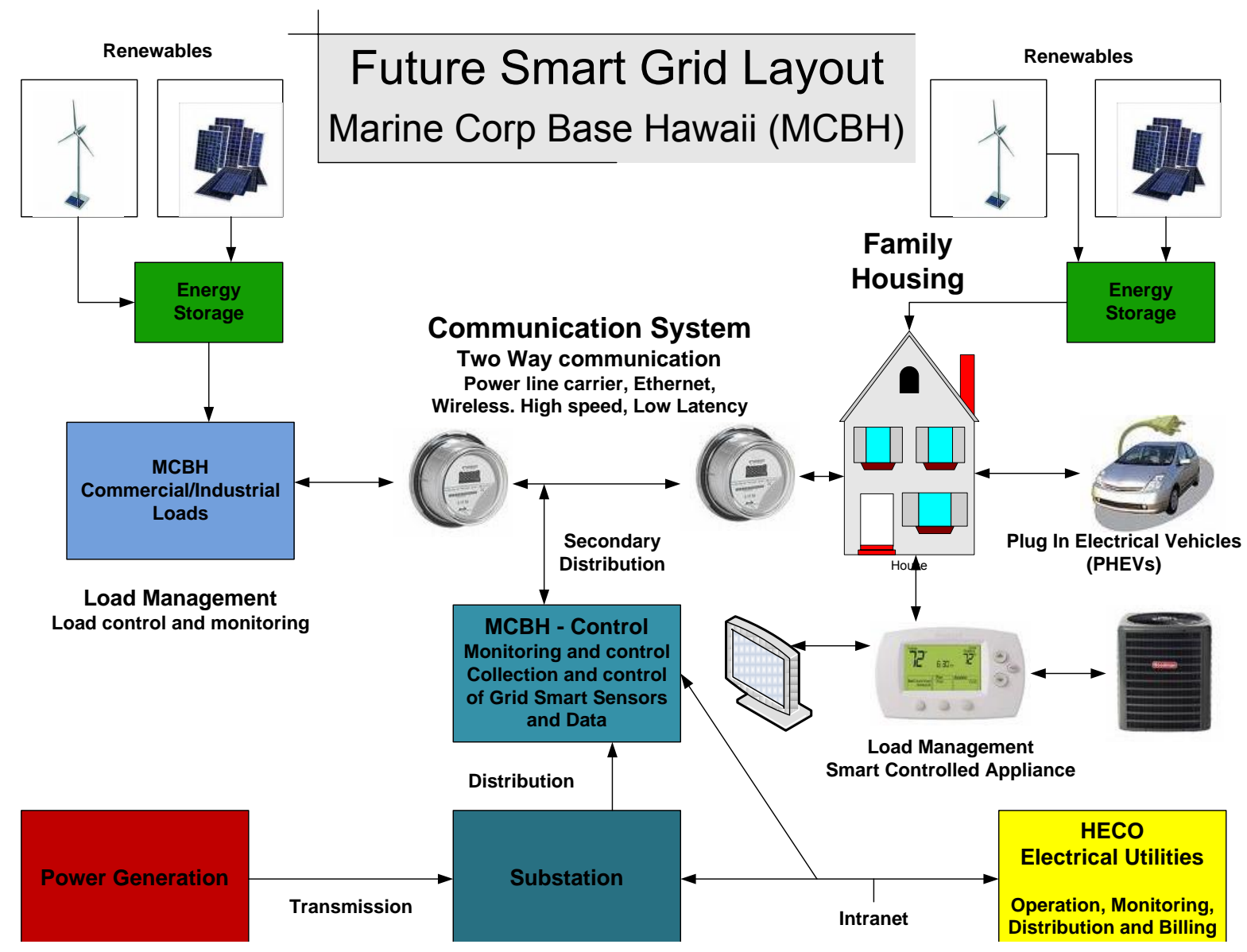

Figure ES.1. Smart Grid Architecture for the MCBH/FCH Development

\section{Energy Efficiency Strategies Recommendations}

In existing redeveloped family housing (and in future projects), the following can be implemented to reduce energy and demand:

- For the solar/thermal-assisted water heaters in the units:

- Disconnect the lower heating element and let the system run on the top element one only. This would allow the lower part of the tank to be heated primarily by solar and if the tank empties to less than $1 / 3$, the upper element will come on.

- Alternatively, set the lower thermostat to $10^{\circ} \mathrm{F}$ to $20^{\circ} \mathrm{F}$ degrees cooler than the upper thermostat. Either of these strategies could net a $10 \%$ to $40 \%$ increase in solar-driven water heating with a similar decrease in electric resistance water heating.

- Install interlock or proximity switches in windows and patio doors that will turn off the air conditioning when windows and patio door are opened for more than a pre-set period of time. This could be integrated with a security/fire alarm system. 
- In future/new redevelopment projects (such as Waikulu Section \# 4), a number of strategies can be deployed for improved building efficiency and demand response. These include (in no particular order):

- Install high-quality, light-emitting diode (LED) recessed can/down-lighting technology. Savings compared to fluorescent can lighting is $\sim 20$ watts/fixture.

- Install LED streetlights and walkway lights in neighborhoods.

- Consider "solar tubes" (natural light transmission via reflective tubes) in areas that are normally dark due to the house layout and lack of windows.

- Specify "super-insulated" windows. These are windows with a minimum R-5 that achieve a whole window National Fenestration Rating Council (NFRC) U-value of 0.19 and $0.22 \mathrm{Btu} /-\mathrm{ft}^{2 \circ} \mathrm{F}$ for fixed and double hung windows, respectively and that demonstrate solar heat gain coefficients (SHGC) greater than 0.30 .

- Correctly size the air conditioners (A/C) commensurate with any additional energy/load saving strategies implemented in future new construction.

- Coordinate with DOE programs that are developing "smart grid" appliance and thermostats to specify appliances (and thermostat) with low-cost chips that allow automatic control based on load on the grid and/or grid instability and that is communicated via the smart grid architecture. Examples of potential control features of a smart chip include 1) a dryer that will only heat during off-peak times; 2) a dishwasher that will delay startup until off-peak times: 3) a refrigerator that will only defrost when truly required and only in off-peak times; 4) a hot water tank that will learn usage pattern and delays heating water during on-peak times; and 5) a thermostat that delays activating the $\mathrm{A} / \mathrm{C}$ during or near on-peak periods.

- Under such a smart grid architecture, the occupants can receive real-time price information via the in-home display and could adjust energy use based on price and/or allow the system to automatically control equipment. 


\section{Acronyms and Abbreviations}

\begin{tabular}{|c|c|}
\hline $\mathrm{A} / \mathrm{C}$ & air conditioner \\
\hline AT & air-tight \\
\hline CCE & central control equipment \\
\hline CFL & compact fluorescent lighting \\
\hline CRU & control and receiving unit \\
\hline DCSI & Distribution Controls Systems Inc. \\
\hline DOE & Department of Energy \\
\hline DRU & Aclara $^{\mathrm{TM}}$ Demand Response Unit \\
\hline DSI & disconnect switch interbase \\
\hline DSOM & decision support for operations and management \\
\hline EBS & Energy Billing Systems Inc. \\
\hline $\mathrm{FCH}$ & Forest City Housing \\
\hline GE & General Electric \\
\hline HAN & home area network \\
\hline HECO & Hawaiian Electric Company \\
\hline $\mathrm{IC}$ & insulated ceiling \\
\hline IHD & TWACS In-Home Display \\
\hline $\mathrm{kV}$ & kilovolt \\
\hline $\mathrm{kW}$ & kilowatt \\
\hline LCD & liquid crystal display \\
\hline LED & light emitting diode \\
\hline $\mathrm{MCBH}$ & Marine Corps Base Hawaii \\
\hline MTU & modulation transfer unit \\
\hline NFRC & National Fenestration Rating Council \\
\hline NYSE & New York stock exchange \\
\hline $\mathrm{OE}$ & DOE's Office of Electricity \\
\hline OMU & outbound modulation unit \\
\hline PHEV & plug-in hybrid electric vehicle \\
\hline PNNL & Pacific Northwest National Laboratory \\
\hline PPV & public-private venture \\
\hline PV & photovoltaic \\
\hline RCE & remote communications equipment \\
\hline SCE & substation communications equipment \\
\hline SHGC & solar heat gain coefficients \\
\hline TWACS $®$ & Two-Way Automatic Communication System \\
\hline
\end{tabular}





\section{Contents}

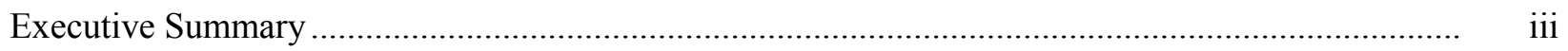

Acronyms and Abbreviations ........................................................................................... vii

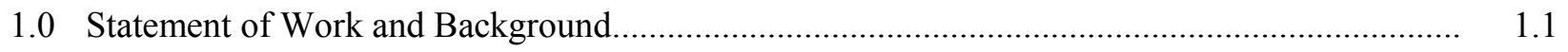

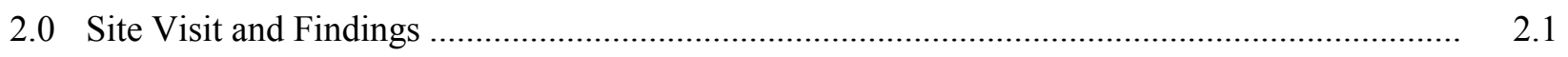

2.1 MCBH Electrical Service ....................................................................................... 2.1

2.2 Energy Consumption and Load Profiles .................................................................... 2.2

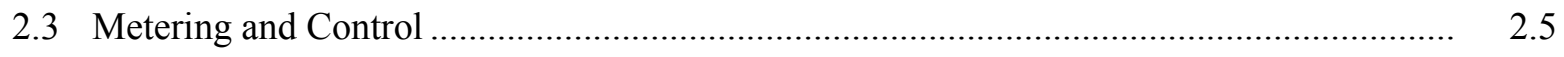

2.4 Current Efficiency and Load Management Strategies in FCH....................................... 2.9

3.0 Recommendations for Load Control and Demand Response Strategies ................................. 3.1

3.1 HECO Load Management Programs................................................................................. 3.1

3.2 Load Management and Demand Response Strategies for FCH Implementation................ 3.3

3.2.1 Implement TWACS Capability for Selected Load Control with Residential Smart Meter and Home Area Network.............................................................. 3.3

3.2.2 Demonstrate GE Ecomagination ${ }^{\mathrm{SM}}$ Home Monitoring System............................... 3.4

3.2.3 Implement Additional Demand Response/Efficiency Strategies in New/Future Family Housing Redevelopments ....................................................................... $\quad 3.5$

3.3 MCBH Installation Load Management Recommendation ............................................. 3.6

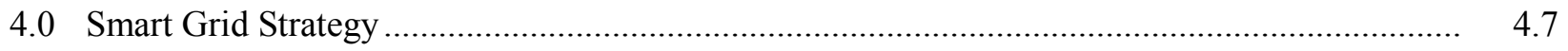

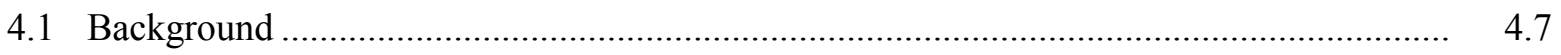

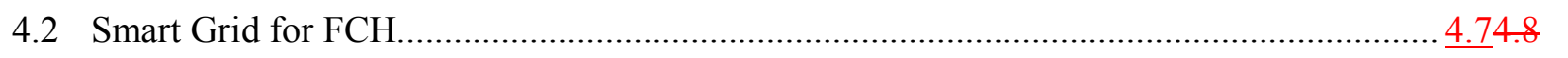

Appendix A - Representative Family Housing at MCBH ........................................................... A. 1

Appendix B - Servicing Utility Perspective on Smart Grid ........................................................ B. B. 


\section{Figures}

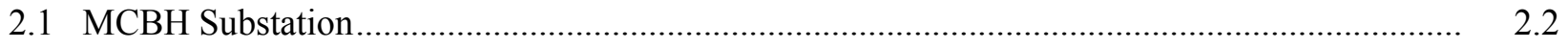

2.22008 Energy Consumption Profile for the MCBH ................................................................ 2.3

2.32008 Daily Load Profile for the MCBH …......................................................................... 2.4

2.4 July 7, 2007 Peak Day Load Profile for the MCBH ........................................................... 2.4

2.5 MCBH Switch Gear Control Room Master TWACS Control System ...................................... 2.6

2.6 MCBH TWACS Master Control Diagram and Illustration of Potential Application in Family

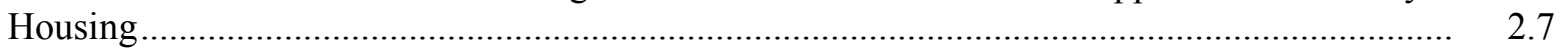

2.7 Outbound Modulation Units and Modulation Transfer Units at MCBH Control Room ............. 2.8

2.8 MCBH TWACS-Interfaced Commercial Buildings Billing Meter 8and Transponder ............... $\quad 2.8$

3.1 Air Conditioner with EnergyScout Canon Technologies Controller .......................................... 3.2

3.2 Landis+Gry Meter Base and TWACS DSI Interface ............................................................. 3.3

3.3 TWACS In-Home Display Configuration and Interface ...................................................... 3.4

4.1 Smart Grid Architecture for the MCBH/FCH Development ................................................. 


\subsection{Statement of Work and Background}

The Department of Energy's (DOE's) Pacific Northwest National Laboratory (PNNL) was tasked by the DOE Office of Electricity (OE) to recommend load reduction and grid integration strategies, and identify additional demand response (energy efficiency/conservation opportunities) and strategies at the Forest City Housing $(\mathrm{FCH})$ redevelopment at Pearl Harbor and the Marine Corps Base Hawaii (MCBH) located at Kaneohe Bay. The goal was to provide FCH staff a path forward to manage their electricity load and thus reduce costs at these FCH family housing developments.

At the recommendation of the FCH staff, the initial focus of the work was at the $\mathrm{MCBH}$, given that the $\mathrm{MCBH}$ has a demand-ratchet tariff, relatively high demand ( 18 MW) and a commensurate high blended electricity rate (26 cents/kWh) compared to the Pearl Harbor development and, given the limited resources and time, was considered the better site for recommending energy and load reduction strategies. Therefore, PNNL focused primarily on $\mathrm{MCBH}$, and this report summarizes recommendations for FCH and $\mathrm{MCBH}$.

Forest City Enterprises, Inc., a $\$ 10.9$ billion publicly traded real estate company, ${ }^{1}$ is principally engaged in the ownership, development, acquisition, and management of commercial and residential real estate throughout the United States. A NYSE-listed real estate company based in Cleveland, Ohio, its portfolio includes interests in retail centers, apartment communities, office buildings and hotels throughout the United States

Forest City Enterprises, Inc., operating under a public-private venture (PPV) in Hawaii is providing high quality and affordable housing. FCH will be building and managing Hawaii military homes and communities on Oahu for the next 50 years. One of the goals of the FCH developments is to construct and operate military family housing redevelopments using sustainable principles and with low utility operating costs. FCH is currently managing 2317 units at the MCBH and 4251 units at Pearl Harbor. Appendix A contains photos of representative homes in neighborhoods at $\mathrm{MCBH}$.

The Navy and Marine sites on Oahu are served electricity by Hawaiian Electric Company (HECO). HECO is working closely with the FCH developers to provide technical assistance and utility customer incentives to reduce energy use and help FCH manage load. Therefore, HECO is a partner in this activity and the recommendations.

\footnotetext{
${ }^{1}$ www.forestcity.net
} 



\subsection{Site Visit and Findings}

PNNL staff visited Oahu the week of September 28, 2008. The purpose of the visit was to survey the $\mathrm{FCH}$ development at the $\mathrm{MCBH}$, meet with $\mathrm{MCBH}$ installation (the commercial area of the installation) staff as well as FCH and HECO staff to:

1. Discuss installation and family housing metering, load profiles, and controls (Section 2.1)

2. Understand the current efficiency and load management strategies for MCBH family housing (Section 2.2)

3. Determine the potential future load management and demand response opportunities from programs that may be offered by HECO (Section 3.1)

4. Recommend a smart grid architecture for the FCH that would also integrate with the MCBH installation (Section 3.2)

5. Suggest MCBH installation (commercial buildings) load management strategies (Section 3.3)

6. Provide recommendations for future load management/demand response strategies for the FCH family housing (Section 4).

\subsection{MCBH Electrical Service}

The MCB installation is served by HECO at a single substation. Transmission is via a 138-kilovolt $(\mathrm{kV})$ line with two $46-\mathrm{kV}$ feeders to the three transformers in the main substation. Figure 2.1 shows the MCBH substation. 


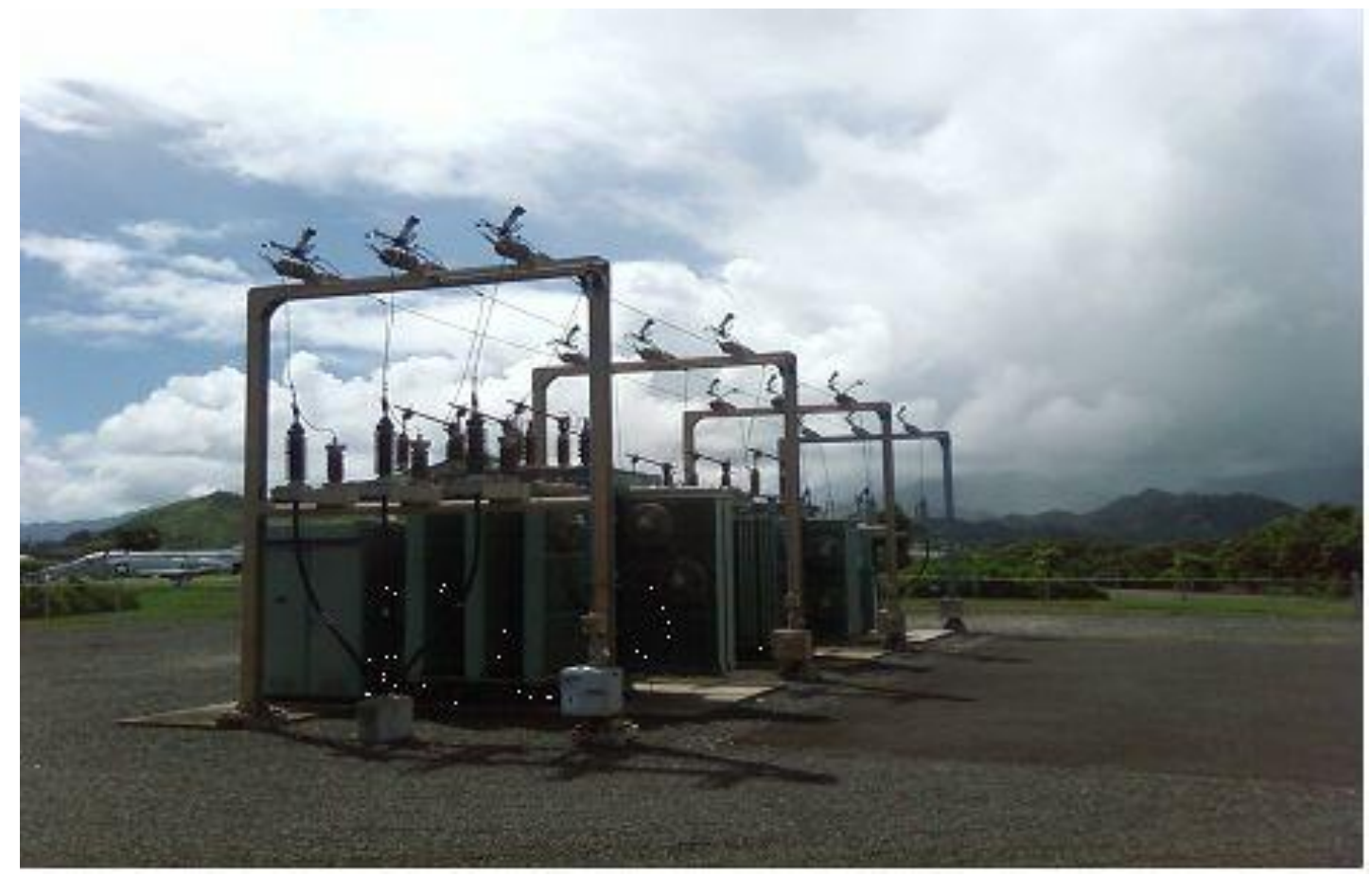

Figure 2.1. MCBH Substation

There are two HECO-owned meters inside the switch room building for the entire installation. The main installation and family housing are on a single tariff and account, and the monthly bill is based on readings from the 2 meters.

\subsection{Energy Consumption and Load Profiles}

The daily consumption profile for the MCBH for 2008 through September is given in Figure 2.2. The maximum peak occurs for MBCH in July-August. 


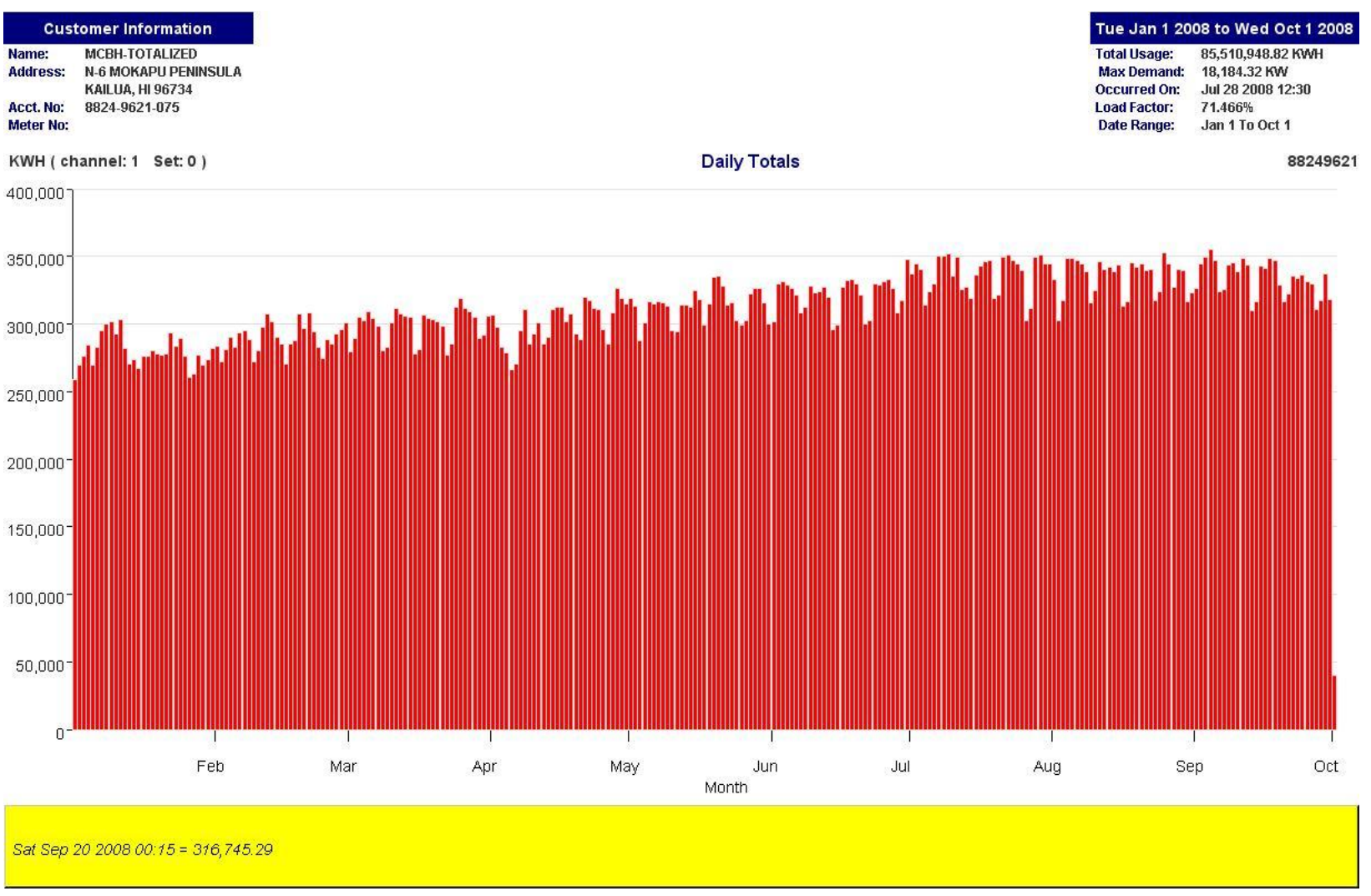

Figure 2.2. 2008 Energy Consumption Profile for the MCBH

The daily load profile for the MCBH (entire installation) for 2008 through September is given in Figure 2.3. The maximum demand for the installation occurs in July-August, with the peak of $18,184 \mathrm{~kW}$ occurring July 28, 2008. For comparison, the peak for 2007 for the MCBH was 18,207 kW on July 7 at $1: 35 \mathrm{pm}$, as shown in Figure 2.4. From Figure 2.3, the base load for the MCBH during July-August is $\sim 15,500 \mathrm{~kW}$ and thus a load reduction of $\sim 3000 \mathrm{~kW}(\sim 17 \%)$ may be achievable with load management strategies in both the FCH and MCBH buildings.

The cost of electricity for the family housing at MCBH is summarized below:

- September 2007: $\$ 0.17 / \mathrm{kWh}$ (blended energy+demand)

- August 2008: \$0.26/kWh (blended energy+demand)

- Average electricity cost Sept 2007: \$307/unit; August 2008: \$433/unit 


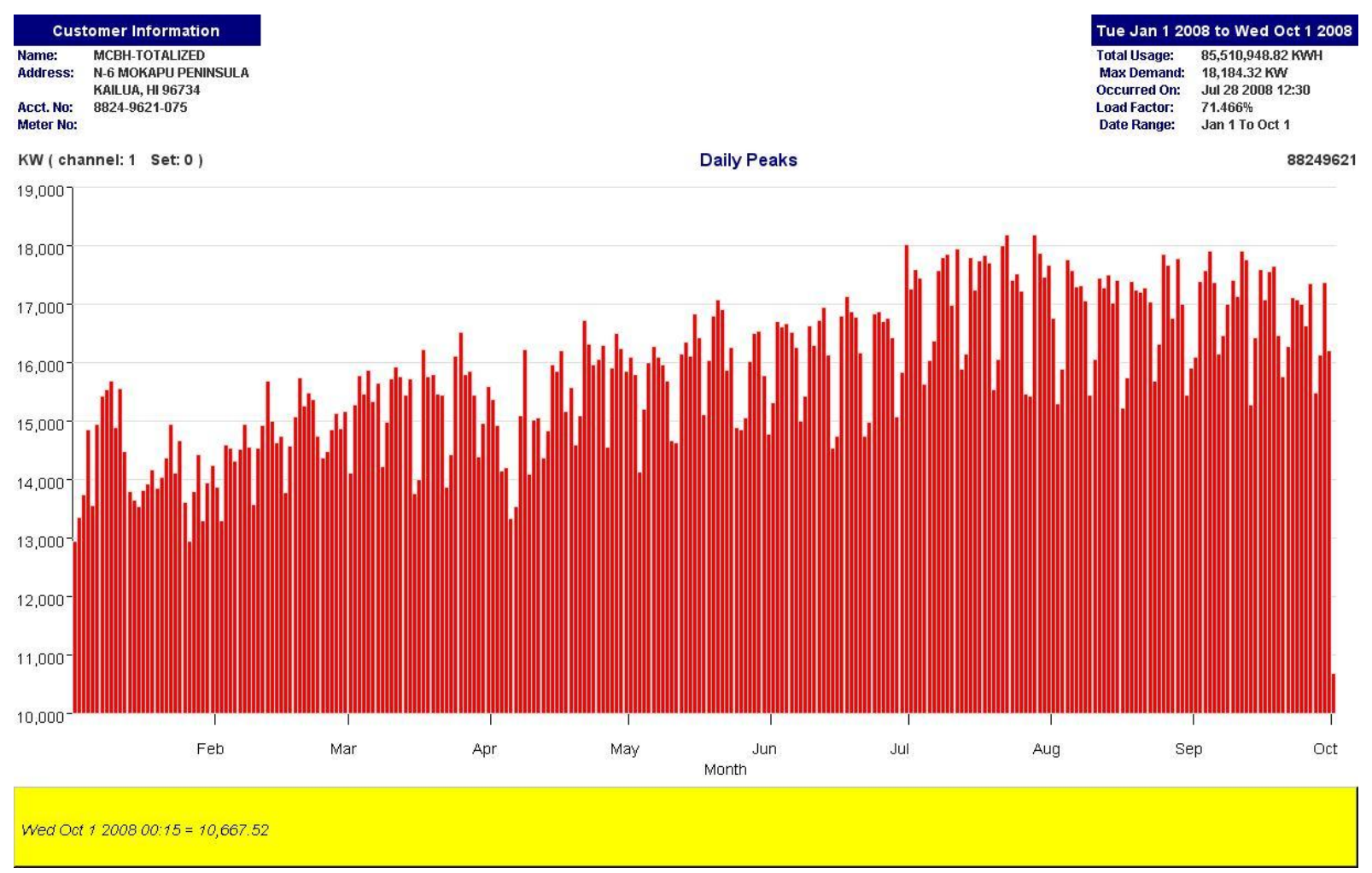

Figure 2.3. 2008 Daily Load Profile for the MCBH
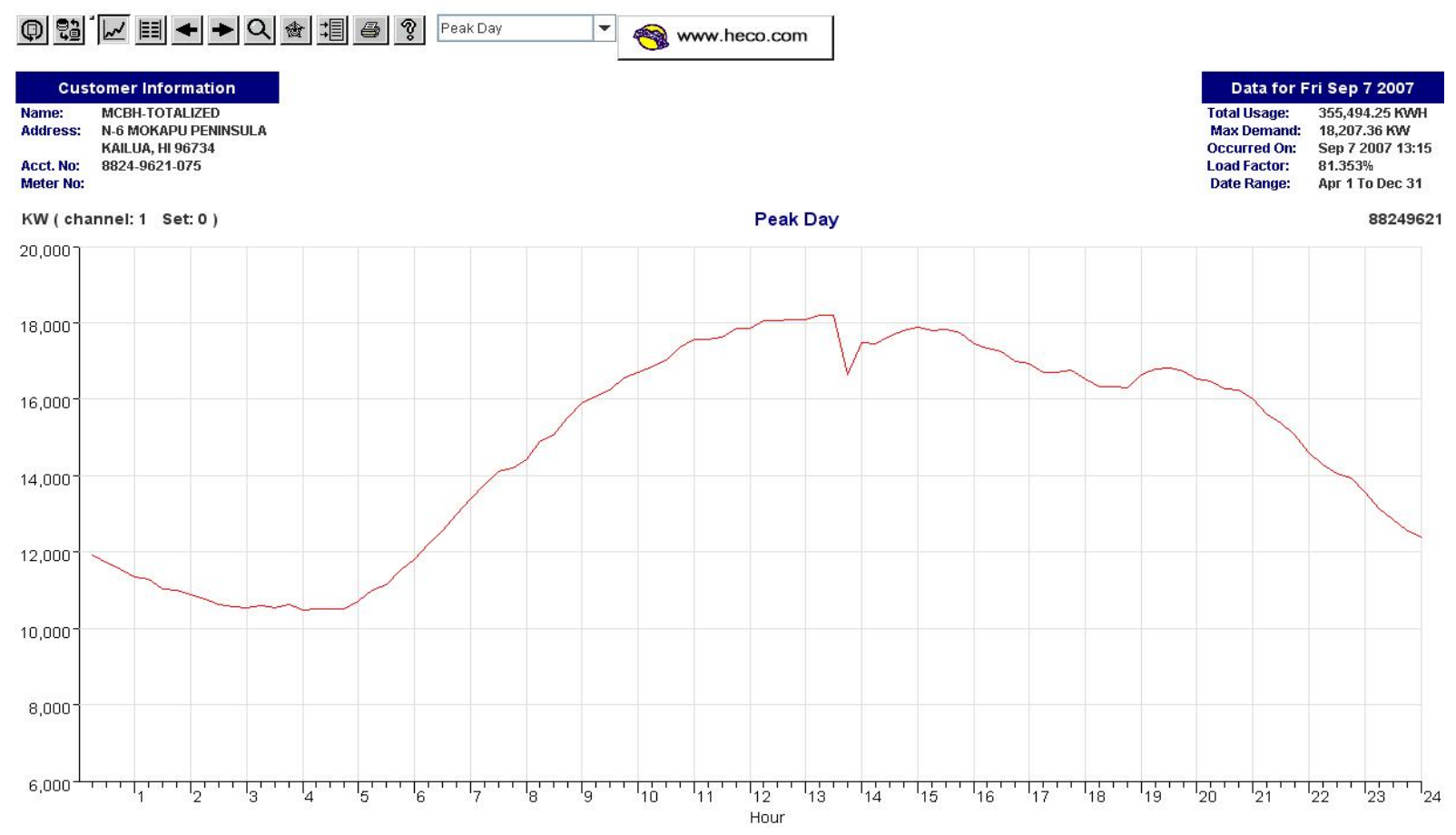

Figure 2.4. July 7, 2007 Peak Day Load Profile for the MCBH 
On average, family housing at $\mathrm{MCBH}$ has contributed $\sim 36 \%$ to the $\mathrm{MCBH}$ total energy consumption over the last year. Thus, a significant load reduction in family housing can have considerable impact on the overall site load.

\subsection{Metering and Control}

FCH is planning on implementing electrical (billing) metering on family housing at MCBH similar to that implemented at the FCH family housing developments at Pearl Harbor Navy Base. FCH uses Energy Billing Systems Inc. (EBS) meters ${ }^{1}$ and remote data collection service to collect data on housing energy usage. FCH uses these data from the Pearl Harbor Navy Base family housing to show the energy efficiency of its new highly efficient constructed homes over the older housing units.

The meters and data collection is designed to meet Department of Defense military housing privatization requirements. Residents in privatized military family housing will typically be provided with a utility allowance that is determined after a one year analysis of utility consumption in a similar home. That allowance represents the average utility usage in that housing type each month. Residents with utility consumption below the allowance will receive the difference in a form of credit. Residents whose utility consumption exceeds the allowance will be required to pay the difference out of pocket. The ultimate goal of this program is the responsible use of utilities in family housing. The intended result is increased resources for family housing communities as a result of the savings gained through responsible utility usage.

For metering, data collection and control at the MCBH (commercial buildings on the installation), the energy management staff employs a Two-Way Automatic Communication System $\left(\right.$ TWACS $^{\circledR}$ ) which is a product of Distribution Control Systems Inc. (DCSI). The TWACS control system includes Modulation Transfer Units (MTUs) and Outbound Modulation Units (OMUs) and is set up in the switch gear and control room building as the master control system as shown in Figure 2.5. A diagram of how the system is linked and could be applied in family housing is shown in Figure 2.6. The current/existing MTUs and OMUs for the system are shown in Figure 2.7.

The TWACS at MCBH utilizes an Aclara ${ }^{\mathrm{TM}}$ power-line carrier for equipment networking and control for the commercial buildings on the installation. The communications ride on the utility distributed power lines to the base using the 60 -Hertz signal.

The energy management staff at MCBH have installed a complete Aclara demand response system ${ }^{2}$ and are currently placing commercial electrical meters throughout MCBH to monitor - and eventually control (primarily on/off) - major loads in the buildings. These meters will also be able to monitor and $\log$ the load usage and provide energy/load profile characteristics of the MCBH buildings. Each meter is installed with a transponder meter for remotely acquiring billing and other strategic information about their building usage patterns. Figure 2.8 shows the meters and transponder that will be used by the $\mathrm{MCBH}$ on selected installation commercial buildings.

\footnotetext{
${ }^{1}$ Energy Billing Systems, Inc., Colorado Springs, CO. www.energybillingsystems.com/

${ }^{2}$ The system includes the meter data management software (MDMS) system of Nexus Energy Software, an Aclara Power-Line Systems ${ }^{\mathrm{TM}}$ Inc. powerline carrier, the Aclara RF Systems ${ }^{\mathrm{TM} I n c}$., and Aclara Software ${ }^{\mathrm{TM}}$ Inc. $\underline{\text { www.aclaratech.com }}$
} 


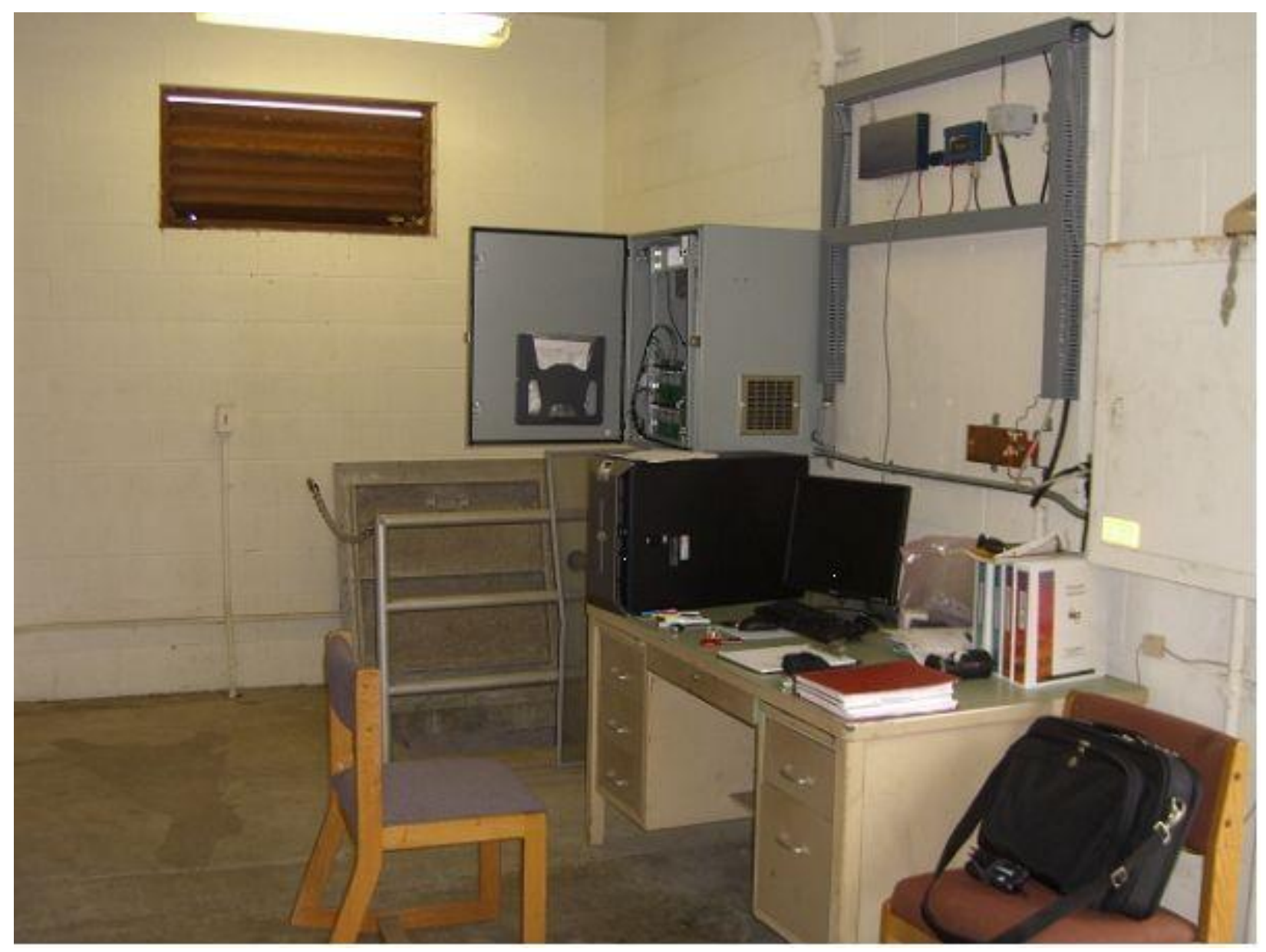

Figure 2.5. MCBH Switch Gear Control Room Master TWACS Control System 

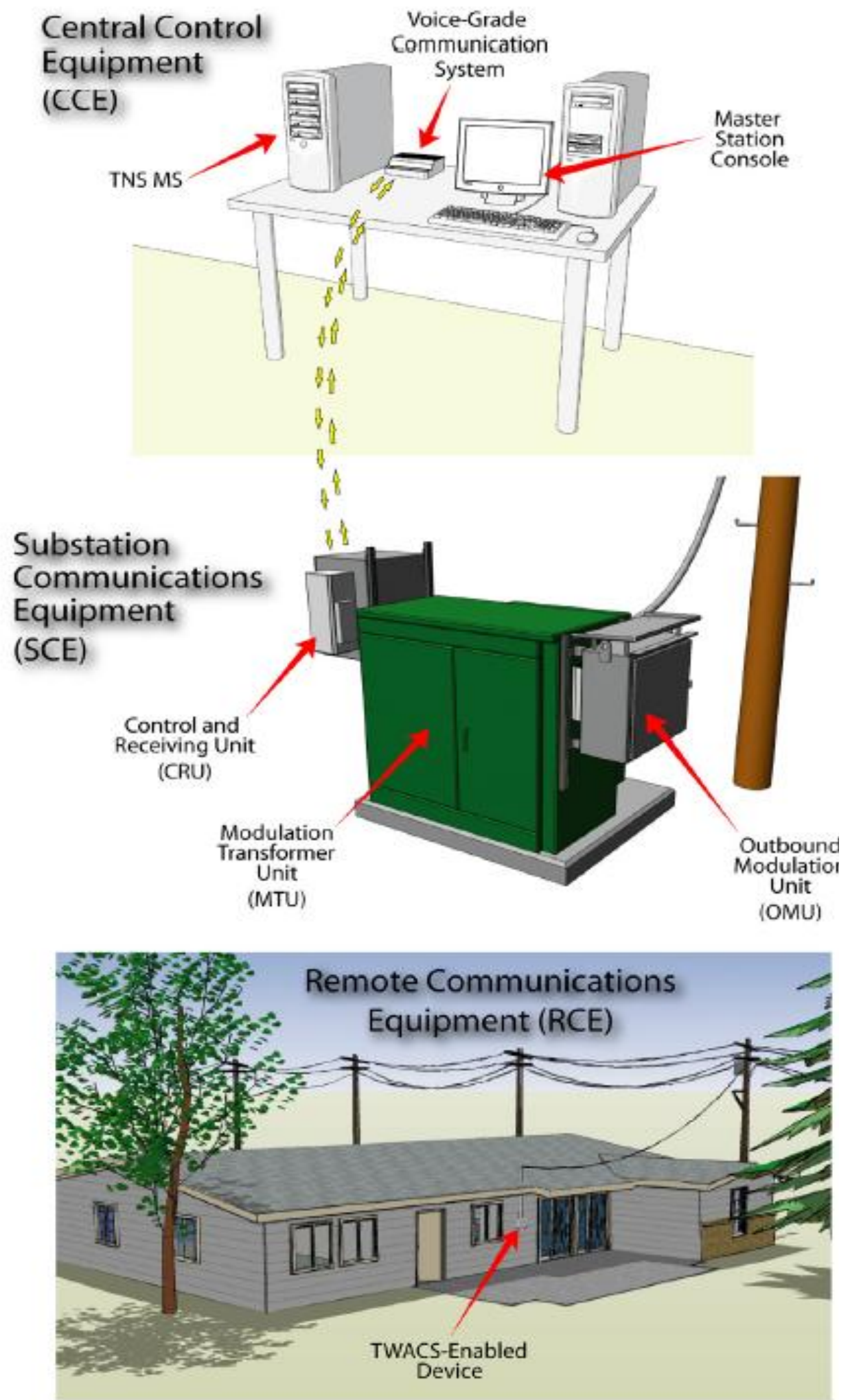

Figure 2.6 MCBH TWACS Master Control Diagram and Illustration of Potential Application in Family Housing 


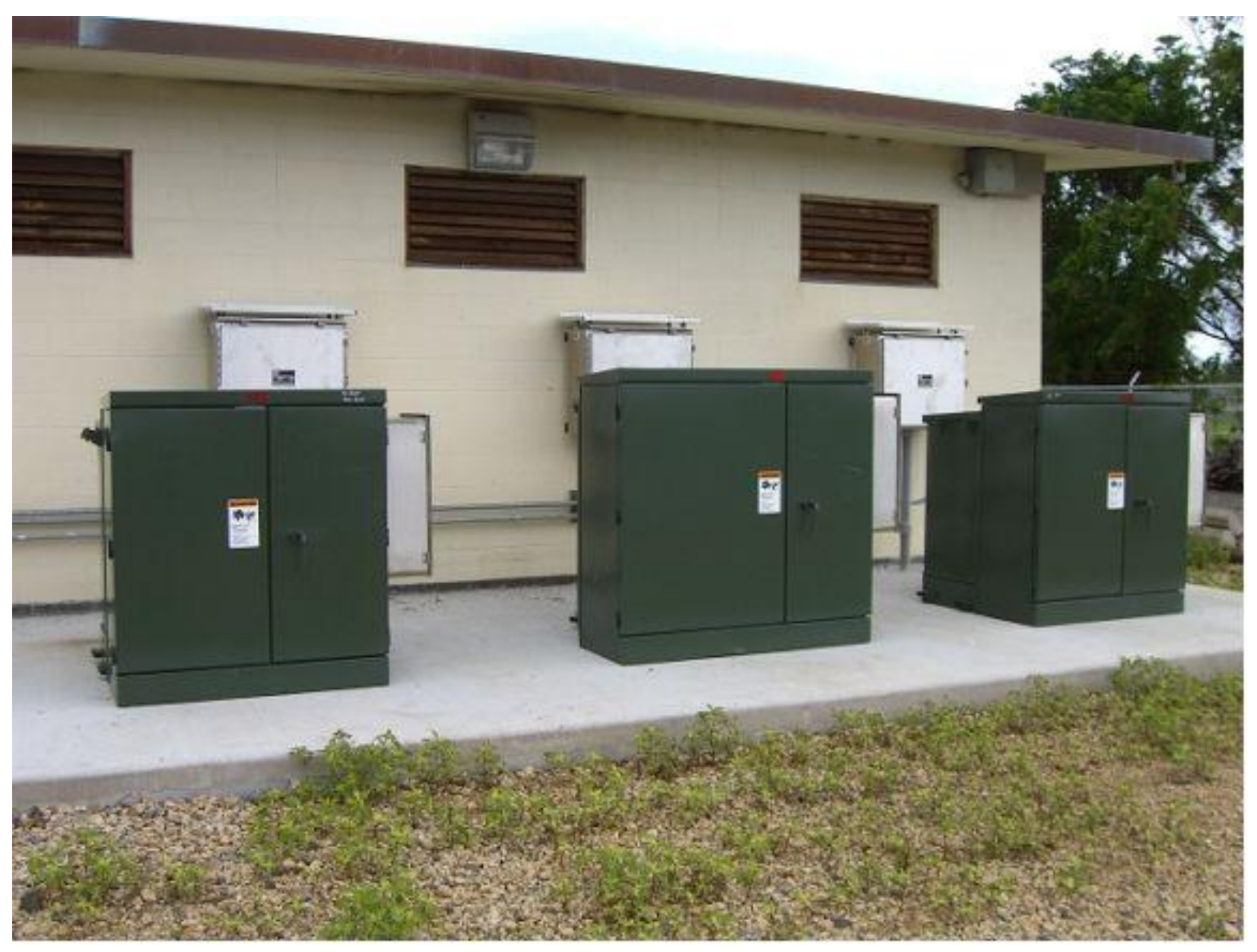

Figure 2.7. Outbound Modulation Units and Modulation Transfer Units at the MCBH Control Room
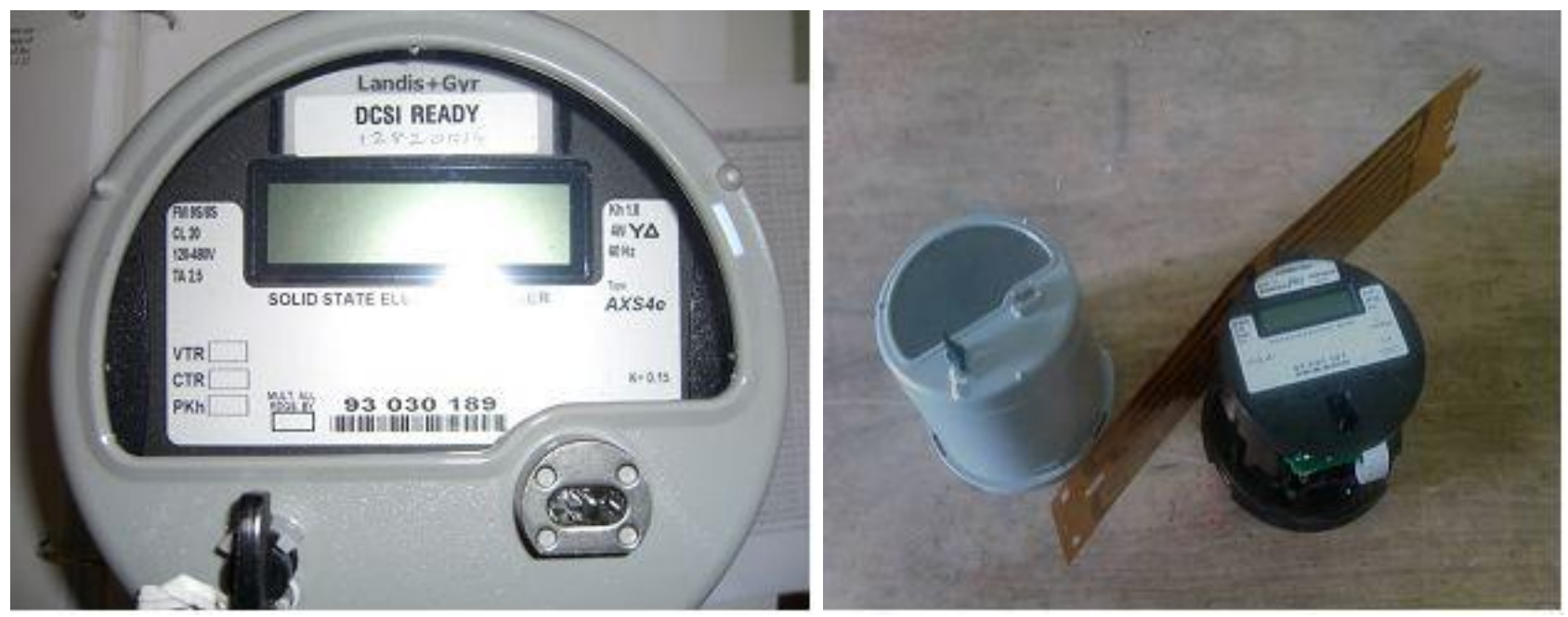

Figure 2.8. MCBH TWACS-Interfaced Commercial Buildings Billing Meter 8 and Transponder 
The TWACS and Aclara systems are not currently used in family housing but could be expanded to incorporate a TWACS Home Area Network (HAN) to allow occupants to make intelligent choices on how they use energy. As with the commercial side of the installation, the HAN would use power-line carrier technology to provide two-way communication with family housing. The suite of TWACS HAN equipment would include the following:

- Aclara Demand Response Unit (DRU)

- Programmable Control thermostat

- TWACS In-Home Display (IHD)

More detail on how to incorporate and extend TWACS in family housing as part of a "smart grid" architecture is given in Section 3.

\subsection{Current Efficiency and Load Management Strategies in FCH}

FCH staff have undertaken a considerable effort to reduce overall energy consumption and load in redeveloped family housing units and neighborhoods. Among the energy saving and demand reduction features incorporated into the construction of each refurbished or new home are the following:

- R-25 insulation in a "ventless" attic

- Composite tile roofing with reflective aluminum backing

- R-19 batt wall insulation ${ }^{1}$

- Whirlpool ENERGY STAR refrigerator, clothes washer (Cabrio ${ }^{\circledR}$ series), and dishwasher (with supplementary heater). The units are also supplied with Whirlpool clothes dryers.

- Carrier high-efficiency air conditioner (14 SEER/11.5 EER) with programmable thermostat

- ENERGY STAR windows ${ }^{2}$

- Vinyl siding for exterior

- Insulated garage doors

- Solar/thermal assisted Rheem electric water heater with circulating pump and thermal bypass

- $\mathrm{CFL} / \mathrm{FL}$ lighting throughout.

\footnotetext{
${ }^{1}$ FCH will be demonstrating Foametix ${ }^{\circledR}$ light density, polyurethane spray-applied foam insulation system in the Mololani Neighborhood homes at MCBH. See www.foametix.com. Foametix has an estimated value of R-25.

${ }^{2}$ ENERGY STAR windows have a U-Value $\leq 0.65$. If Window to Floor Area (WFA) $\leq 25 \%$, then the Solar Heat Gain Coefficient (SHGC) must be $\leq 0.40$; OR If WFA $>25 \%$, then SHGC must be $\leq(8.4 \%$ x Floor Area)/Window Area, where WFA $=($ Total Window Area $) /($ Total Floor Area $)$.
} 



\subsection{Recommendations for Load Control and Demand Response Strategies}

As described in Section 2, FCH is taking a number of significant steps to integrate efficiency and load management into the MCBH family housing redevelopment. At the same time, the entire MCBH installation has the capability to monitor and manage loads of commercial buildings through the TWACS system. The installation load control strategy will use TWACS and the Aclara demand response system will be implemented over time once the installation has better characterized the primary load centers (buildings) and what loads to control in those buildings.

In the interim, there are a number of actions FCH can take in family housing to reduce its (significant) share of the installation load and thus reduce the installation peak-demand (that occurs in the July-August time period), overall site demand, demand charges and energy consumption and costs.

These recommended load reduction and demand response strategies are given below in three parts: those that can be implemented in FCH family housing as part of a partnership with HECO utilizing HECO's existing programs (Section 3.1); those that are current technology and can be implemented in family housing outside of utility programs and are compatible with $\mathrm{HECO}$ and $\mathrm{FCH} / \mathrm{MCBH}$ goals (Section 3.2); and strategies for the MCBH installation (commercial buildings). All of the recommendations are then tied together in a proposed "smart grid" strategy described in Section 4.

\subsection{HECO Load Management Programs}

HECO currently has installed a significant number of "EnergyScout" remotely controlled load shedding systems in the residential sector on the Island of Oahu. For a small monthly incentive ( $\$ 3 / \mathrm{kW}$ for water heaters; $\$ 5 / \mathrm{kW}$ for air conditioners), HECO can activate the EnergyScout to disable air conditioners and/or electric water heaters for a short time period to reduce load periods. ${ }^{1}$ Figure 3.1 shows an air conditioner with the EnergyScout Canon Technologies controller. ${ }^{2}$

The EnergyScout system allows HECO to curtail customer load (e.g., turn off customer's air conditioner for a short time period) when:

- HECO anticipates insufficient generation (minimum 1-hr pre-notification provided)

- There is a sudden drop in the electrical system frequency (instantaneous, no pre-notification)

As with most all of the housing on the Island of Oahu, there is no heating in MCBH family housing and thus air conditioning is the largest energy load. Therefore, FCH has been working with HECO to install the EnergyScout on all new/redeveloped family housing units at MCBH. HECO will therefore control the $\mathrm{A} / \mathrm{C}$ use in the $\mathrm{FCH}$ units as part of the load management strategy for the Island of Oahu.

\footnotetext{
${ }^{1}$ Air conditioning load in HECO service territory has increased from $16 \%$ in 1980 to 57\% 2006. Currently, HECO has installed 25,000 EnergyScouts resulting in a 17MW demand reduction.

${ }^{2}$ Canon Technologies is a part of Cooper Power Systems: www.cooperpowereas.com
} 


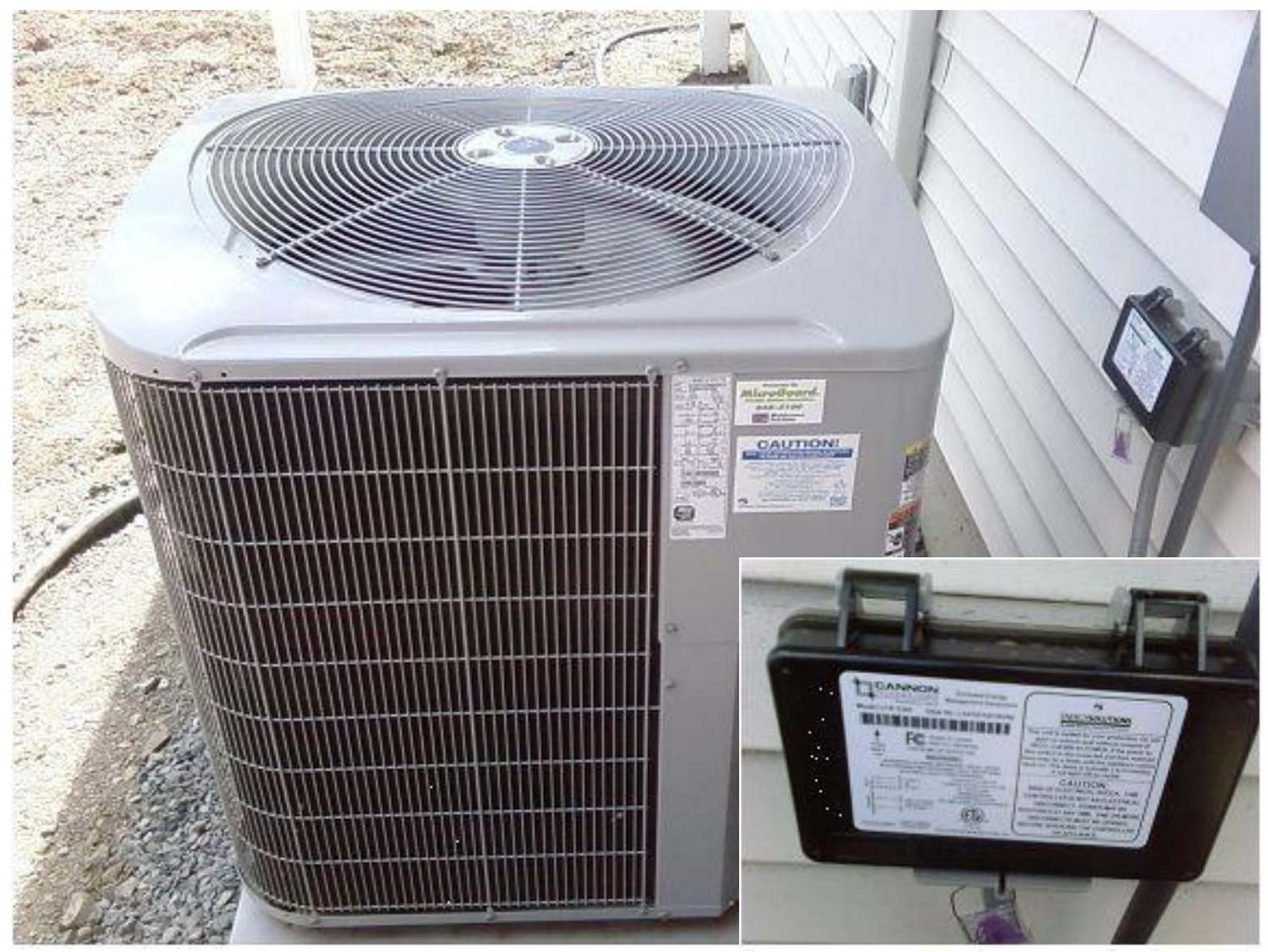

Figure 3.1. Air Conditioner with EnergyScout Canon Technologies Controller

HECO, PNNL, FCH and Cannon Technologies representatives discussed deploying the EnergyScout as a load management strategy at $\mathrm{MCBH}$. There was general agreement that load control for the family housing at MCBH using the EnergyScout could be deployed through a strategy of gently rolling an off and on cycle throughout family housing when load is nearing the peak at the $M C B H .{ }^{1}$ This strategy could be initiated immediately for the current installed EnergyScout systems given there is no up-front investment required by FCH. Such a strategy can also be integrated with other recommendations given below.

Current rooftop solar/PV systems for individual units may not be cost-effective today for FCH even with generous state and federal tax incentives. However, should HECO develop an incentive program for solar/PV (as they at one time were considering in early 2000), then FCH should take advantage of any program. In any event, FCH should continually undertake cost/benefit analysis and plan for PV installations - and the integration of PV into the family housing infrastructure.

\footnotetext{
${ }^{1}$ Current HECO strategy for control with the EnergyScout is to control systemwide peak on Oahu which may not be co-incident with MCBH peak. Thus the discussion and agreement with HECO to deploy EnergyScout control in family housing specifically for assisting with managing the MCBH peak load.
} 


\subsection{Load Management and Demand Response Strategies for FCH Implementation}

There are a number of actions that the FCH staff can take to reduce load and save energy and energy costs now with the current inventory of family housing as well as in future redevelopment of neighborhoods. These are summarized below. The strategies are categorized as applicable to the current inventory, to future redevelopment, or both.

\subsubsection{Implement TWACS Capability for Selected Load Control with Residential Smart Meter and Home Area Network}

Using the existing TWACS infrastructure capability at MCBH, FCH can plan strategies that allow trimming of utilization during peak usage times in current and future developments. Load control would allow remote turn-off of components within a residence (as well as commercial buildings on the installation) that draw substantial levels of power during peak period. This shedding of power would allow the control of peak demand and reduction of overall load for the entire installation.

To enable the extension of the current MCBH TWACS system into family housing at MCBH, each housing unit could be equipped with a Landis+Gyr FOCUS ${ }^{\text {TM }}$ solid state single-phase 200 amp electrical meter (EMT-3F) - or equivalent two-way communications meter - capable of accepting the TWACS DSI as well as having compatibility with the EBS remote billing system currently used by FCH. The DSI is a two-way power-line communication system and addressable disconnect switch (See Figure 3.2). The DSI combines the functionality of a 200-amp latched relay with the convenience of the TWACS two-way power line communications system.
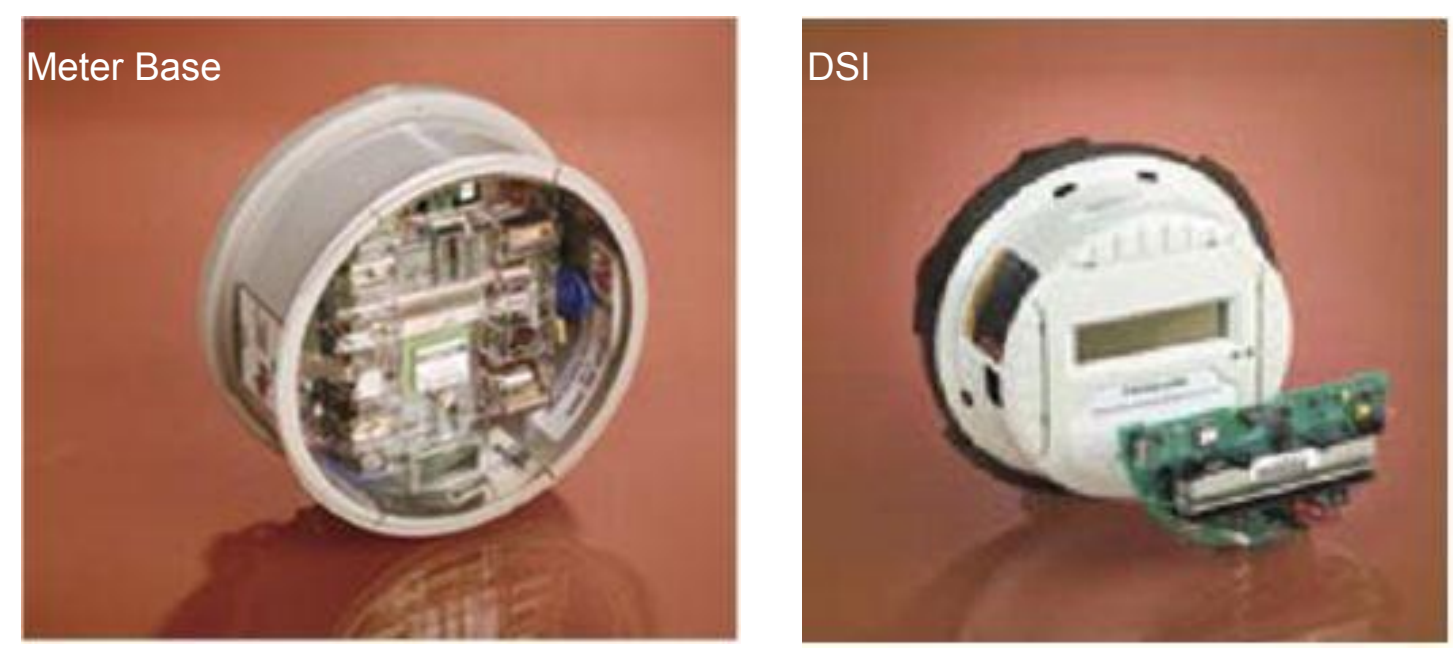

Figure 3.2. Landis+Gry Meter Base and TWACS DSI Interface

The TWACS could be interfaced with the Aclara home area network ( $\mathrm{HAN} f \mathrm{x}$ ) or equivalent in-home display and equipment control system. The HAN $f \mathrm{x}$ employs a variety of intelligent devices such as programmable thermostats and an in-home display (IHD). The TWACS IHD receives messages, alerts, billing, and account status information directly to customers. The IHD plugs into a standard electrical 
outlet. When combined with the UtiliSales ${ }^{\mathrm{TM}}$ master system software, this simple plug-in demand response component keeps customers informed regarding energy saving decisions.

The TWACS IHD system can be expand through a ZigBee ${ }^{\circledR}$ or Z-Wave ${ }^{\circledR}$ wireless communication protocols ${ }^{1}$ to enable the use of ,smart' appliances (see smart appliance discussion below). This system would help customers stay informed about peak pricing, current demand and their own power usage, allowing them to make smart decisions to turn off appliances or allow the ,smart' appliances to automatically be controlled. Figure 3.3 illustrates the TWACS IHD interface.

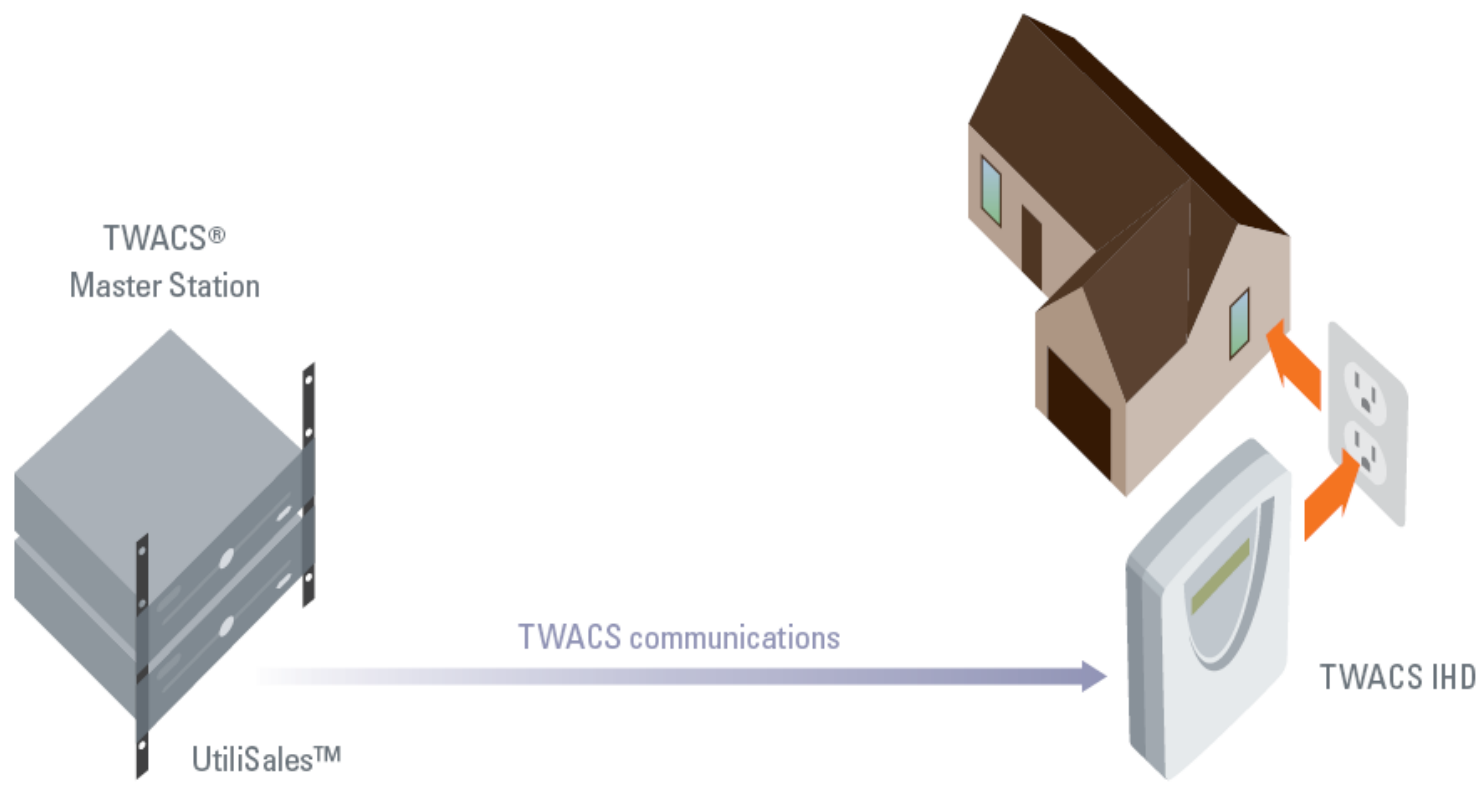

Figure 3.3. TWACS In-Home Display Configuration and Interface

\subsubsection{Demonstrate GE Ecomagination ${ }^{\mathrm{SM}}$ Home Monitoring System}

GE is planning to undertake a "showcase" demonstration of their "Eco-dashboard" home energy and water consumption visualization and control system in a number of FCH homes. The Eco-dashboard is a central feature of GE's ecomagination homebuilder program. The program is an effort to provide comfortable, efficient homes that save homeowners' energy costs while easing the impact on the environment. The GE ecomagination homebuilder program homes are targeted to provide at least a $20 \%$ saving in household energy, water consumption and emissions versus an industry-accepted average new home. These homes will provide significantly more energy efficiency than the minimum levels required for ENERGY STAR qualified homes.

The Eco-dashboard system is designed to interface with a "smart grid" architecture that includes a smart thermostat and smart meter with two-way communications. The system is designed to allow the resident to respond to real-time pricing and control energy use in the home in response to price signals.

\footnotetext{
${ }^{1}$ See www.zigbee.org and www.z-wave.com for details of these systems.
} 
Depending on the configuration and outcome of the demonstration, the system and system communications could possibly be interfaced with the EBS billing system planned for MCBH family housing. As part of the overall MCBH load control strategy, the GE system may also be able to interface with the TWACS should that system be expanded into FCH as part of an overall installation smart grid and peak load control system as discussed in Section 4.

\subsubsection{Implement Additional Demand Response/Efficiency Strategies in New/Future Family Housing Redevelopments}

In future/new redevelopment projects (such as Waikulu, Section \# 4), a number of strategies can be deployed for improved efficiency and demand response. These include (in no particular order):

- Install light-emitting diode (LED) can/down-lighting such as the LR6 or LR4 technology. ${ }^{1}$ These are six- and four-inch diameter recessed insulated ceiling (IC) air-tight (AT) can lights for new or retrofit applications. These 11-watt dimmable fixtures have been independently tested to meet the ENERGY STAR requirements with high efficacy and can save $\sim 20$ watts/fixture over CFL can lights.

- Install LED streetlights and walkway lights in neighborhoods. New commercially available products have entered the market and are currently undergoing independent testing by DOE under its solid state lighting research program.

- Consider "solar tubes" (natural light transmission via reflective tubes) in areas that are normally dark due to the house layout and lack of windows. Examples would be staircases, bathrooms and garages.

- Consider installing interlock or proximity switches in windows and patio doors that will turn off the $\mathrm{A} / \mathrm{C}$ when windows and patio doors are opened. This will reduce the incidence commonly found in family housing where the $\mathrm{A} / \mathrm{C}$ is running with windows/doors open. This practice is common in hotel/motels where the switch is installed on sliding glass doors.

- For those developments scheduled for construction during the 2010-2012 time frame, consider specifying "super-insulated" windows. These are windows with a minimum of R-5 that achieve a whole window National Fenestration Rating Council (NFRC) U-value of 0.19 and $0.22 \mathrm{Btu} / \mathrm{h}-\mathrm{ft}^{2}-{ }^{\circ} \mathrm{F}$ for fixed and double hung windows, respectively and that demonstrate solar heat gain coefficients (SHGC) greater than 0.30 . DOE is currently undertaking a program to bring these windows into the marketplace at a cost-effective price point above current ENERGY STAR-qualified windows.

- Correctly size the air conditioner $(\mathrm{A} / \mathrm{C})$ commensurate with any additional energy/load saving strategies implemented in future new construction.

- Coordinate with DOE and the private sector manufacturers to consider specifying appliances (specifically dishwashers, refrigerators and dryers) and appliances with Grid Friendly ${ }^{\mathrm{TM}}$ control chips $^{2}$ to allow automatic regulation of appliance use based on load on the grid and/or grid instability. These chips can be programmed to:

- Allow a clothes dryer that will only heat during off-peak times.

- Control a dishwasher that will delay startup until off peak times.

\footnotetext{
${ }^{1}$ LR6 and LR4 LED can lights are available from several retailers @ $~ \$ 65-75 /$ ea in quantity.

${ }^{2}$ See www.gridwise.pnl.gov for a description of Grid Friendly appliances.
} 
- Allow occupants to receive real-time price information through a broadband internet connection and automated equipment that could adjusts energy use based on price.

- Control thermostats.

\subsection{MCBH Installation Load Management Recommendation}

PNNL did not survey the buildings and facilities on the MCBH installation for potential load management strategies. Given the MCBH commercial buildings represent $\sim 64 \%$ of the load, there is considerable incentive and reason to implement load management and demand response strategies.

PNNL has been involved in implementing successful load management strategies and systems at several marine corps bases on the mainland that are applicable to the MCBH installation. Specifically PNNL has designed and deployed a decision support for operations and management (DSOM) system in the commercial facilities at the Marine Corps Base in Beaufort, SC and Paris Island, SC ${ }^{1}$. At Marine Corp Air Station, Beaufort, SC-PNNL uses a 40-layer, 75-building site-wide demand side management program that works with the main feeder (billing) meter and the site-wide energy management control system. This system results in a 1-megawatt load shedding scheme (10\% of its peak demand).

At Parris Island Recruit Depot, Beaufort, SC-PNNL installed a similar DSOM system that is interfaced with 3 megawatts of cogeneration. Both bases have been operating the DSOM system for several years and are saving considerable money by reducing peak demand.

\footnotetext{
${ }^{1}$ See www.pnl.gov.dsom for more detailed information on the DSOM system and results.
} 


\subsection{Smart Grid Strategy}

"Smart Grid" is a term that has many definitions and can be defined differently by utility stakeholders, businesses, engineers, academics and politicians. In general terms, smart grid refers to improved electricity supply originating from major power plant generating centers and delivered to customers. Smart grid techniques are also complex due to the infrastructure that produces and deliveries energy and the various loads that consume energy.

\subsection{Background}

Typical utilities provide one way flow of electricity from remotely located generation stations to consumers over transmission and distribution grids. Because power generation must match instantaneous demand, electric power infrastructure must be built to accommodate the peak anticipated load on the system. On a time-aggregated basis, peak loads may be experienced, perhaps, for only a few hundred hours or less in an average year ( 1 year $=8760$ hours). For the balance of the year, the power delivery system is typically operating considerably below its rated capacity. Yet, as new consumers are added in the normal course of load growth, the capacity of the power generation and delivery system must be increased to meet the expected growth in peak load.

Among other attributes, the evolving implementation of smart grid technologies allows a more efficient use of utility assets. A primary value of the Smart Grid is to use consumer load response as an interactive means of system control. The utility encourages consumers to participate in reducing peak loads and producing other system benefits using the communication of real-time energy costs and other incentives to motivate the cooperation of end-users. Automated load shedding at times when demand peaks and other system stresses occur using "grid-friendly" appliances is another facet of smart grid operations that has multiple benefits. In aggregate, smart grid technologies can provide a rapid return on investment by increasing the utilization of current infrastructure assets and, thereby, deferring the need for adding future capacity.

New grid infrastructure (the "smart grid") will require two-way flows and communication, customer integration and distribution of technology. Distributed generation is the use of small-scale power generation technologies located close to the load being served, capable of lowering costs, improving reliability, reducing emissions and expanding energy options. New grid structures will also include distributed generation that will be required to meet the increasing use of renewable energy. A new grid infrastructure that will incorporate two way flows of energy and communication will also have to be a smarter grid. A transformation to smart grid technologies will be needed to achieve renewable energy integration and produce energy efficient control. Additional discussion of smart grid from the perspective of a servicing utility is given in Appendix B.

\subsection{Smart Grid for FCH}

The smart grid solution for FCH will require more than an off-the-shelf product solution. The basic concept of smart grid as applied to $\mathrm{FCH}$, is to add monitoring, analysis, control, and communication capabilities to the electrical delivery system to maximize the throughput of the system while reducing the energy consumption. Ideally, this architecture should build from any existing infrastructure including communications, metering, and control systems (such as the HECO EnergyScout). In the near future a 
smart grid requirement will produce price signals that will be relayed to "smart" home controllers or end-consumer devices like smart thermostats, EnergyScouts on air conditioners, and smart (e.g., Grid Friendly) appliances - the home's major energy-users. The devices, in turn, will process the information based on consumers' user patterns, power consumption, load center peaks and the concomitant price signals. The response by the home would be with minimal human intervention. Visualization technology (such as a small LCD device or thermostat control face) in the home will provide the end user information of energy usage, response by equipment as well as optionally provide the resident control over energy consumption in real time.

Even though some of the foundational architecture is already in place at the MCBH (i.e., TWACS), any stand-alone technology is not enough. Standards for communication protocol, secure communication methods, integration, smart meters, etc. are not standard at all across utilities and districts. Smart grid will need to encompass the technology that enables us to integrate, interface with and intelligently control new innovations and others. The ultimate success of the smart grid implementation by FCH depends on the following characteristics of a smart grid architecture:

- Open communication architecture for real-time information and control, allowing every part of the grid to both receive and transmit data and control.

- Simple, with minimum consumer intervention and use of automation.

- Enable real-time communication between the consumer and billing aggregator (generally the utility) so consumers can tailor their energy consumption based on individual preferences, like price and/or environmental concerns. Use of visual information on energy usage and costs in real time.

- Accept future energy systems from virtually any fuel source including solar and wind as easily and transparently as currently being provided.

- Ability to integrating new and emerging grid-impact technologies such as energy storage, and plug-in hybrid electric vehicles (PHEV)

- Readily accept new innovation across a wide spectrum of applications.

- Allow "plug-and-play" innovation wherever and whenever appropriate that can be easily integrated with other technologies and other significant loads (e.g., plug loads) that may be added to the home.

- Sensing and measurement technologies that will support time-of-use pricing and demand-side management

A smart grid architecture that includes the features noted above is shown in Figure 4.1. This includes the potential future integration of renewable energy generation sources at the utility (grid) level as well as at the load center (MCBH and/or FCH) and/or at the individual living units (e.g., rooftop PV). It also includes the integration of storage and PHEV and potential future options to consider integrating.

$\mathrm{FCH}$ is well-positioned to move forward with HECO and MCHB as partners to implement new smart grid technologies and continue to work through the technical and institutional hurdles. HECO is also poised to make the transformation from a centralized, producer-controlled network to one that is less centralized, more distributed and more consumer-interactive. The move to a smarter grid promises to build the relationship with all stakeholders involved and should benefit all consumers of electric power. 
Figure 4.1. Smart Grid Architecture for the MCBH/FCH Development 



\section{Appendix A}

Represent ative

Family

Housing at $\mathrm{MCBH}$ 



\section{Heleloa}

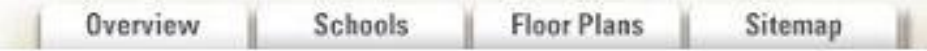

Rich in history, beautiful spacious lots, and a magnificent view. Designated for $\mathrm{O}_{5}$ and above.
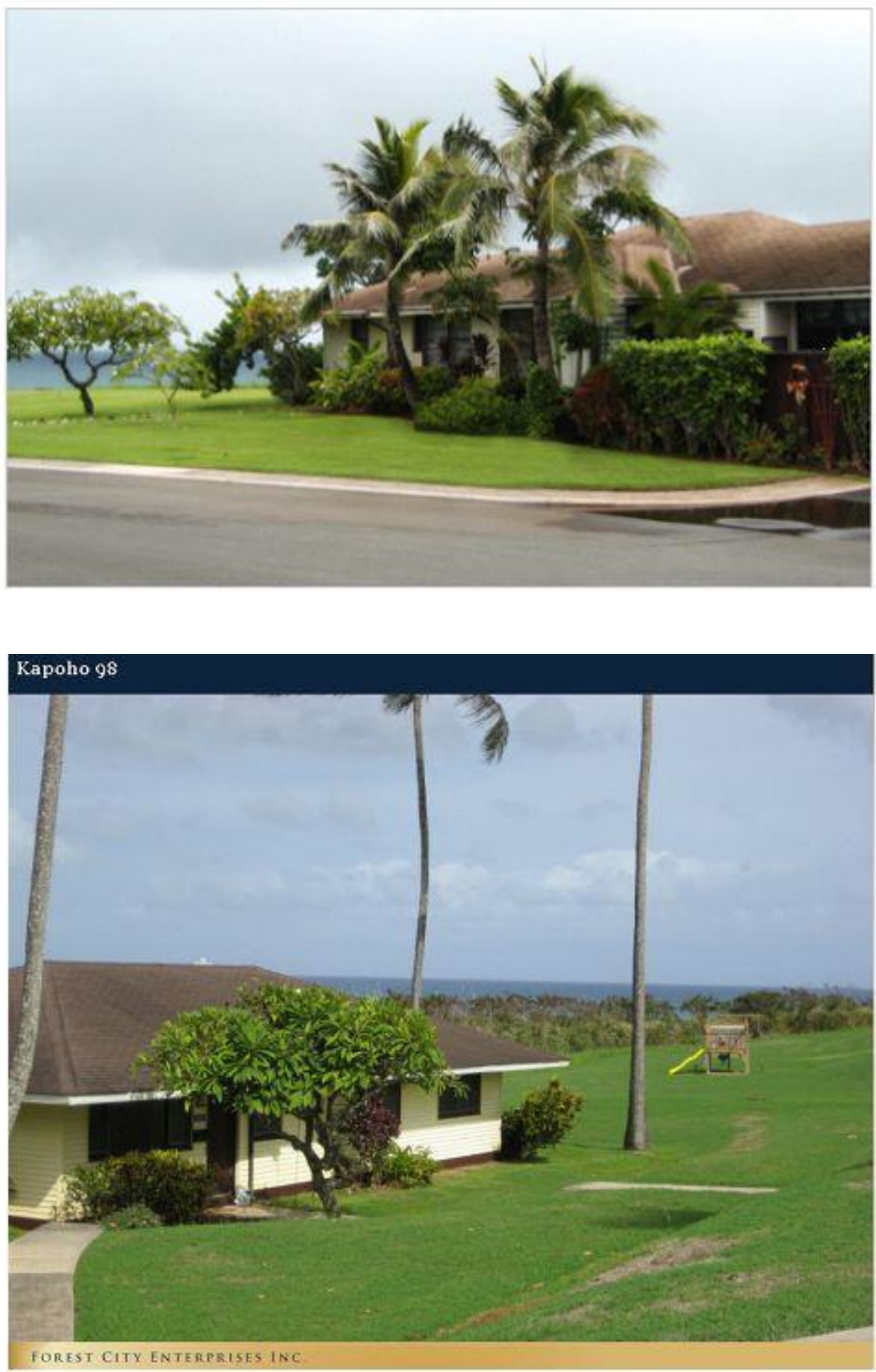

A. 1 


\section{Hawaii Loa}

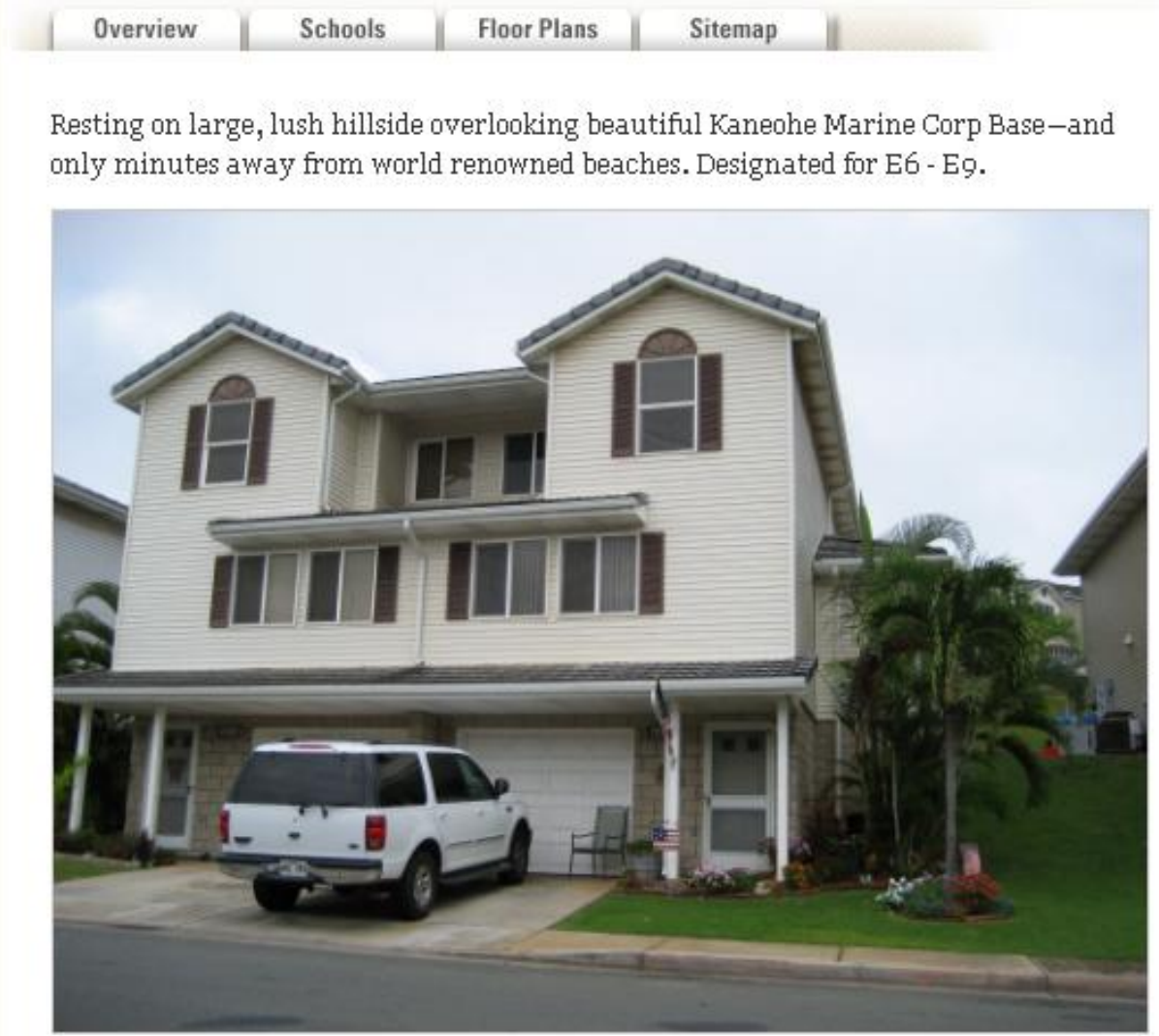

\section{Waikulu 08 001.jpg}

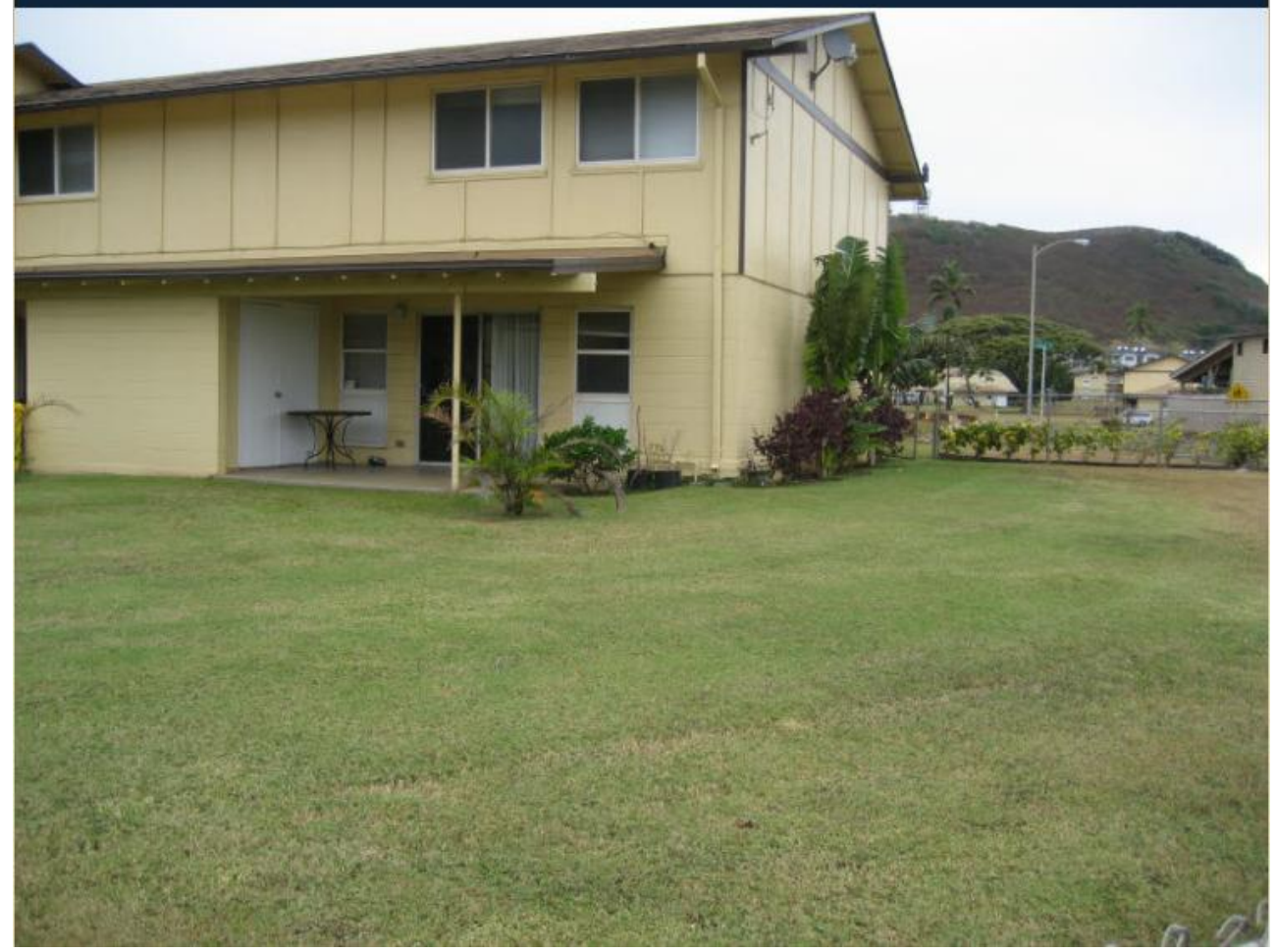




\section{Pa'Honua}

\begin{tabular}{l|l|l|l|} 
Overview & Schools & Floor Plans Itemap
\end{tabular}

Newly developed homes with close knit neighbors and gorgeous scenery. Designated for $E_{1}-E_{5}$.

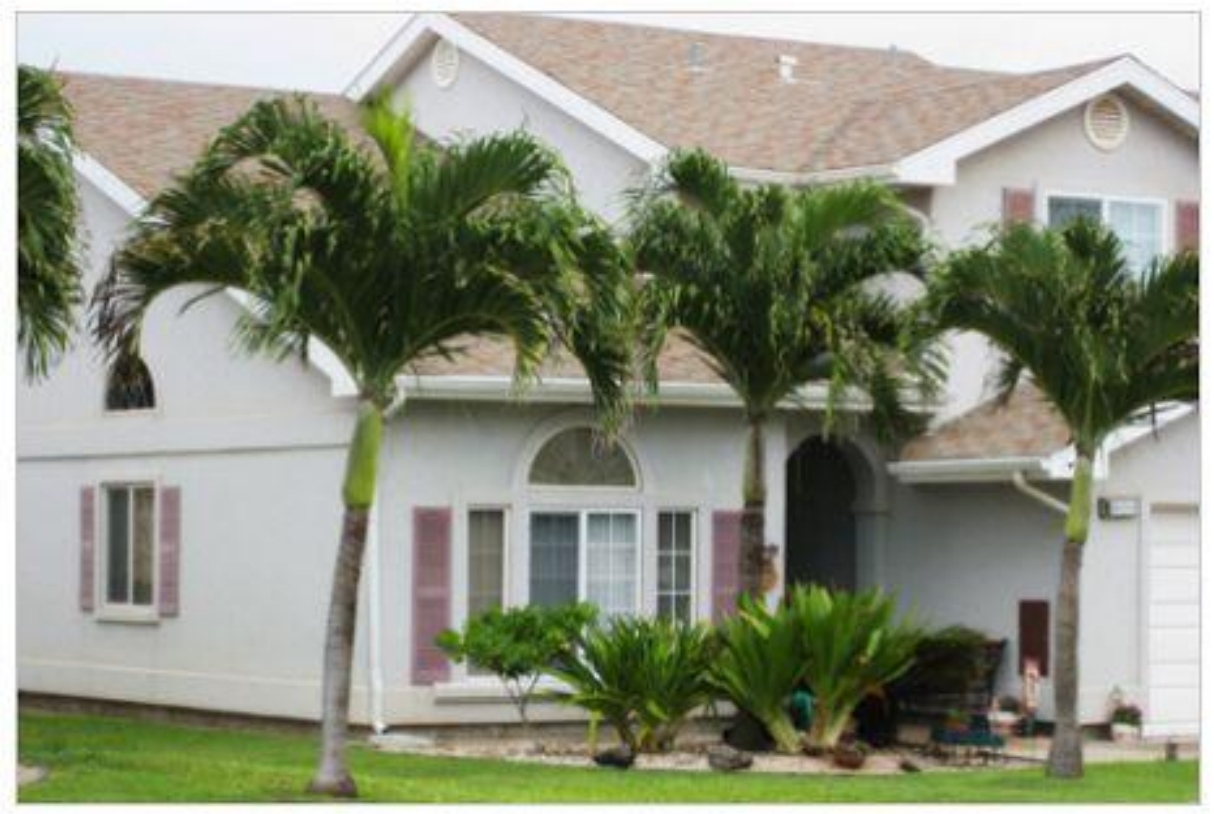

\section{Kaluapuni}

Overview || Schools | Floor Plans | Sitenap

Brand new homes with gorgeous views, currently under construction. Designated for $\mathrm{O}_{4}$ - O5.

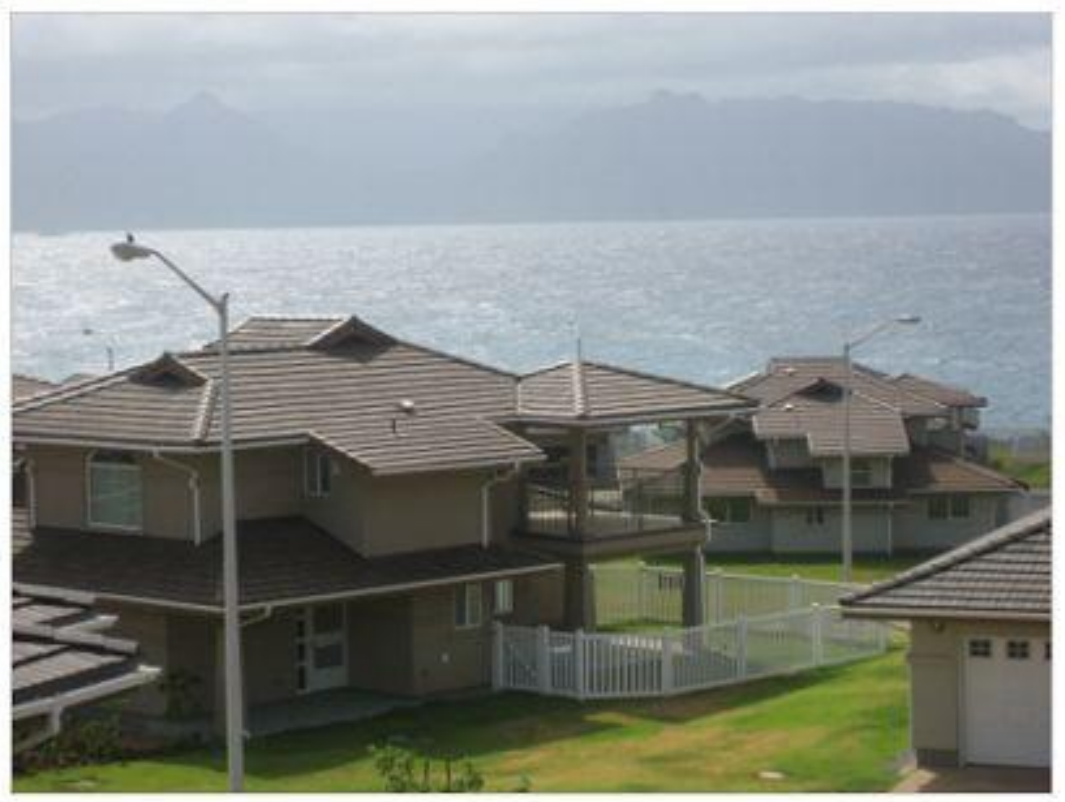




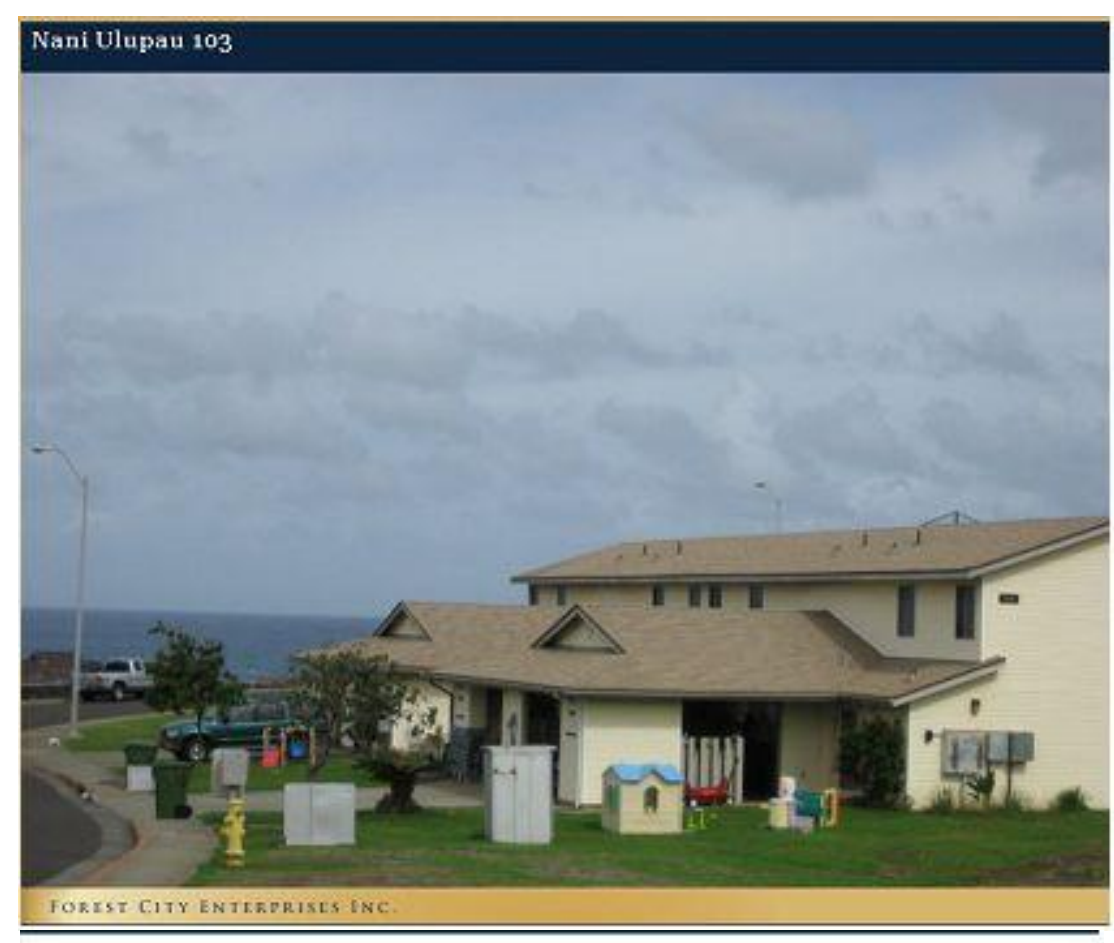

\section{Mololani}

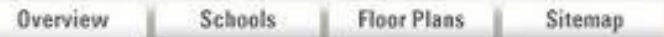

An ocean front community with breathtaking views, you're only walking distance away from the beach.

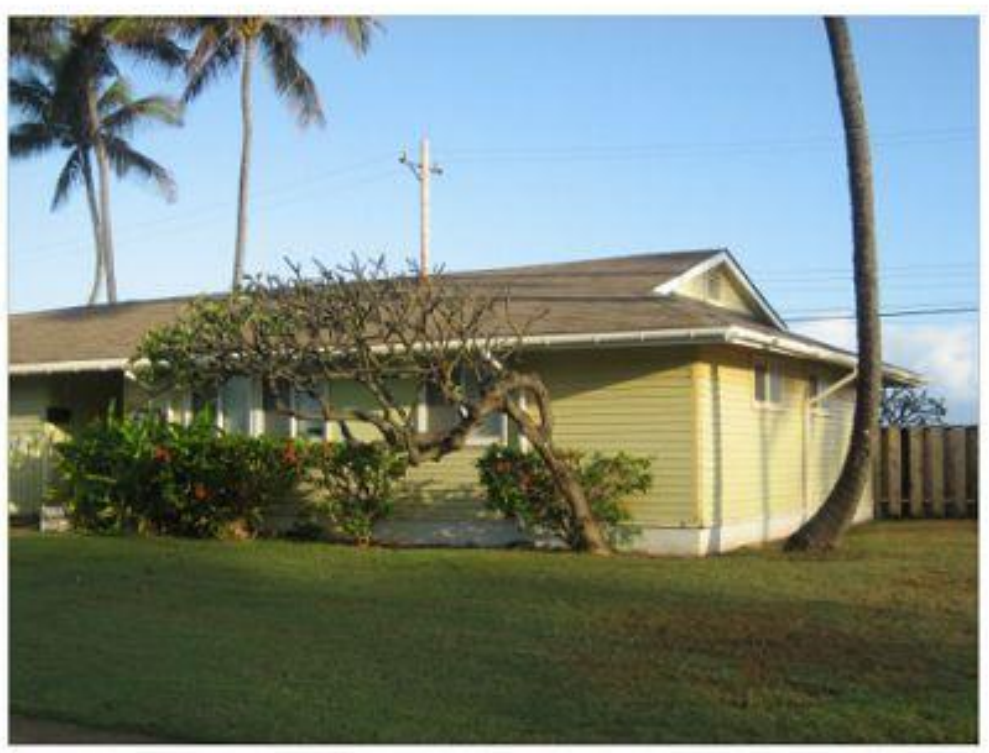

Additional Images
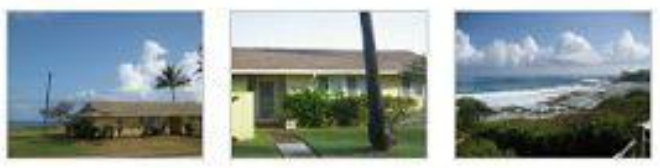


\title{
Appendix B
}

\author{
Servicing \\ Utility \\ Perspectiv \\ e on \\ Smart \\ Grid
}





\section{Appendix B}

\section{Servicing Utility Perspective on Smart Grid}

Whether investor-owned, cooperatively owned, or publically owned, utilities are dedicated to providing electricity needs to their customers by operating, maintaining, and building additional electrical infrastructure and by cooperatively aligning the goals of utilities, consumers and regulators. For a smarter grid to benefit society, it must reduce utilities capital and/or operating expenses today or reduce costs in the future. Smart grid for utilities builds on many of the technologies already used by electric utilities but also adds communication and control capabilities that will optimize the operation of the entire electrical grid. Advanced conductors, electric storage, sensors and controls, distributed intelligence, information and communication, advanced materials, data acquisition, and advanced power electronic will drive the smart grid technology revolution. Smart grid today includes the upgrade and placement of smart meters, cleaner power-producing plants, distribution automation, new technologies to handle plug-in hybrid electric vehicles, solar energy, wind turbines and various non-continuous renewable generating sources. A smarter grid makes it possible to reduce the high cost of handling peak demand. It gives grid operators far greater visibility into the system at a finer bandwidth control of operation and enables them to control loads in a way that minimizes the need for traditional peak capacity. In addition to driving down costs, it may even eliminate the need to use existing peaking plants or build new ones. This will save money and reduce greenhouse gas emissions.

\section{B.1 Commercial and Residential - "Smart Grid” Structures}

For most consumers, energy has long been considered a passive purchase. Without a "power meter watch" who is watching the energy usage in most commercial and residential units? Typically an electric bill is delivered days/weeks/months after the consumption actually occurs. This delay in billing information gives the consumers no visibility into decisions they could be making regarding their energy consumption. The electric bill not only includes energy usage but may also includes the cost to maintain the existing energy infrastructure and could include the increase in oil prices, increasing cost of copper and hardware to keep the power flowing. The smart grid will allow utilities to move electricity around the system as efficiently and economically as possible. It will also allow the homeowner and business owner to use electricity as economically as possible. It will provide the choice and flexibility to manage electrical use while minimizing energy costs. 


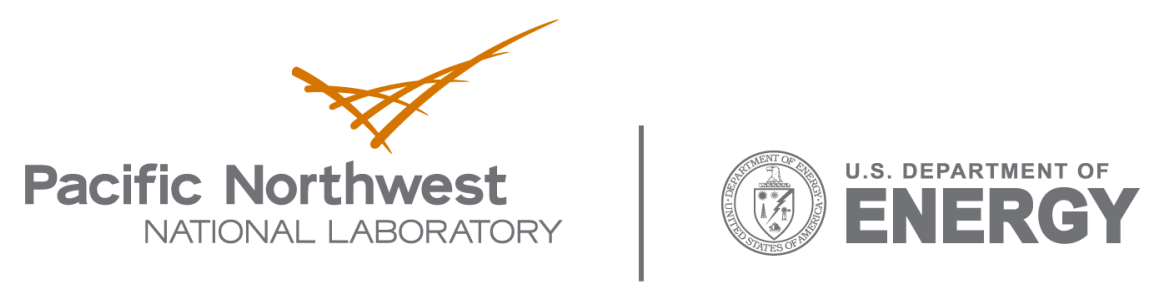

902 Battelle Boulevard

P.O. Box 999

Richland, WA 99352

1-888-375-PNNL (7665)

www.pnl.gov 